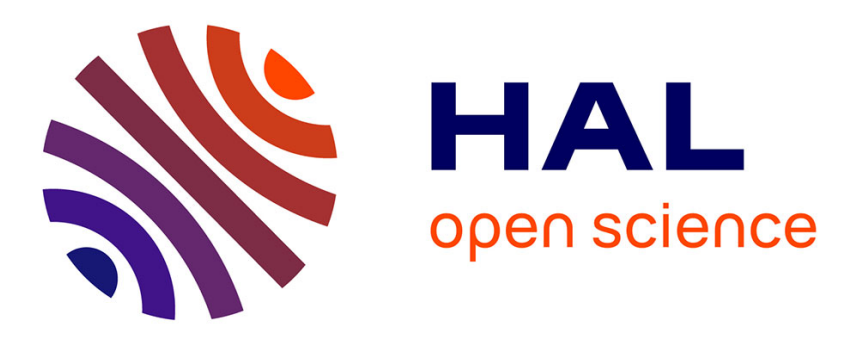

\title{
Validation of an implantable bioink using mechanical extraction of human skin cells: First steps to a 3D bioprinting treatment of deep second degree burn
}

Adeline Desanlis, Marion Albouy, Patricia Rousselle, Amélie Thepot, Morgan

Dos Santos, Céline Auxenfans, Christophe A. Marquette

\section{To cite this version:}

Adeline Desanlis, Marion Albouy, Patricia Rousselle, Amélie Thepot, Morgan Dos Santos, et al.. Validation of an implantable bioink using mechanical extraction of human skin cells: First steps to a 3D bioprinting treatment of deep second degree burn. Journal of Tissue Engineering and Regenerative Medicine, In press, 10.1002/term.3148 . hal-03027633

\section{HAL Id: hal-03027633 https://hal.science/hal-03027633}

Submitted on 4 Dec 2020

HAL is a multi-disciplinary open access archive for the deposit and dissemination of scientific research documents, whether they are published or not. The documents may come from teaching and research institutions in France or abroad, or from public or private research centers.
L'archive ouverte pluridisciplinaire HAL, est destinée au dépôt et à la diffusion de documents scientifiques de niveau recherche, publiés ou non, émanant des établissements d'enseignement et de recherche français ou étrangers, des laboratoires publics ou privés. 


\title{
Validation of an implantable bioink using mechanical extraction of human skin cells: first steps to a 3D bioprinting treatment of deep second degree burn.
}

\author{
Adeline Desanlis ${ }^{3}$, Marion Albouy², Patricia Rousselle ${ }^{4}$, Amélie Thépot ${ }^{2}$, Morgan Dos Santos², \\ Céline Auxenfans ${ }^{3,4}$, Christophe Marquette $^{1 *}$ \\ 1 3d.FAB, Univ Lyon, Université Lyon1, CNRS, INSA, CPE-Lyon, ICBMS, UMR 5246, 43, Bd du 11 \\ novembre 1918, 69622 Villeurbanne cedex, France \\ ${ }^{2}$ LabSkin Creations, Edouard Herriot Hospital, 69437 Lyon Cedex 03, France \\ ${ }^{3}$ Hospices Civils de Lyon, Banque de Tissus et Cellules, Groupement Hospitalier Edouard \\ Herriot, F-69003 Lyon, France \\ ${ }^{4}$ Laboratoire de Biologie Tissulaire et Ingénierie Thérapeutique, UMR 5305, CNRS - Université \\ Lyon 1, Institut de Biologie et Chimie des Protéines, SFR BioSciences Gerland-Lyon Sud, 7 passage \\ du Vercors, Lyon, 69367, France \\ * christophe.marquette@univ-lyon1.fr
}

\begin{abstract}
Clinical grade cultured epithelial autograft (CEA) are routinely used to treat burns covering more than $60 \%$ of the total body surface area. However, although the epidermis may be efficiently repaired by CEA, the dermal layer, which is not spared in deep burns, requires additional treatment strategies. Our aim is to develop an innovative method of skin regeneration based on in situ 3D bioprinting of freshly isolated autologous skin cells. We describe herein bioink formulation and cell preparation steps together with experimental data validating a straightforward enzyme-free protocol of skin cell extraction. This procedure complies with both the specific needs of 3D bioprinting process and the stringent rules of good manufacturing practices. This mechanical extraction protocol, starting from human skin biopsies, allows harvesting a sufficient amount of both viable and growing keratinocytes and fibroblasts. We demonstrated that a dermis may be reconstituted in vitro starting from a medical grade bioink and mechanically-extracted skin cells. In these experiments, proliferation of the extracted cells can be observed over the first 21 days period after 3D bioprinting and the analysis of type I collagen exhibited a de novo production of extracellular matrix proteins. Finally, in vivo experiments in a murine model of severe burn provided evidences that a topical application of our medical grade bioink was feasible and well-tolerated. Overall, these results represent a valuable groundwork for the design of future 3D bioprinting tissue engineering strategies aimed at treating, in a single intraoperative step, patients suffering from extended severe burns.
\end{abstract}

Keywords: 3D bioprinting; Non-cultured skin cells; On-site therapy; Skin cells therapy; Tissue engineering; Wound healing. 


\section{INTRODUCTION}

Severe burn injuries of the skin are difficult to manage due to a large range of combined issues including pain, infection and massive transdermal loss of fluids (Evers, Bhavsar, \& Mailander, 2010). Accordingly, when a burn affects an extended surface of the skin, vital emergency resides in the restoration of the skin barrier function to prevent sepsis and fluid loss (Rousselle, Braye, \& Dayan, 2019). In this context, early surgical excision and autologous skin grafting remain the care standards (Auxenfans et al., 2014; Rowan et al., 2015). However, the limit of this technique, in case of extreme extensive burns, i.e. when more than $60 \%$ of total body surface area is affected, is the limited availability of human skin grafts (Varkey, Ding, \& Tredget, 2015). Skin allografts, harvested from a living or deceased human donor, may be used as temporary wound coverage, promoting re-epithelialization and preparing the wound bed for autograft (Ehrenreich \& Ruszczak, 2006). However, such allografts are rejected within two weeks and need thus to be replaced by autografts (Varkey et al., 2015). In this context, Lyon University Hospital ("Hospices Civils de Lyon") laboratory has pioneered the generation of cultured autologous epidermis (CAE), also known as epidermal sheets, to ensure a permanent wound coverage (Auxenfans et al., 2015). Such a procedure has been applied since 1988. In this protocol, autologous skin cells are extracted from a small skin biopsy $\left(\sim 10 \mathrm{~cm}^{2}\right)$ performed on a burnfree healthy area. From these freshly-extracted cells, a 3 weeks-long culture process is performed in clean room under stringent technical conditions, generating epidermal sheets which may cover more than the total body surface. The positive impact of such grafts on survival has been previously showed and is likely due to a primarily barrier effect allowing to prevent infections and fluid loss (Auxenfans et al., 2015). However, the use of CEA presents several drawbacks which, although not outnumbering benefits, have been unravelled by regular practice. Thus, the fact that 3 weeks are needed in order to obtain CEA (Auxenfans et al., 2014) implies that alternative and less effective covering strategies are required during this period. Last but not least, replacing the epidermis, essential for patient's survival, regenerates only partially the skin, i.e. no dermis, and leads then to the formation of scar tissues which may be retractile (Echinard, 1998).

In addition, while exhibiting efficient barrier properties, grafted CEA does not support a full restoration of the whole skin structure, leading then to frequent occurrence of dystrophic or hypertrophic scars. Finally, the generation of CAE requires two enzymatic dissociation steps that might alter the functions of keratinocytes: i) dispase, a neutral protease used to separate epidermis from the dermis and ii) trypsin which allows the dissociation of keratinocytes and the achievement of a single-cell suspension (Auxenfans et al., 2015). The use of enzymes can be defined as a substantial manipulation of the initial biopsy, forcing the cells preparation to be performed within cell therapy laboratories and classifying them as advanced therapy medicinal products, whose regulations are much more restrictive. These enzymes are known to cleave surface molecules (Autengruber, Gereke, Hansen, Hennig, \& Bruder, 2012) and to degrade cell-cell and cell-matrix adhesion proteins including integrins (Chester, Balderson, \& Papini, 2004; Huang et al., 2010; Yoon et al., 2017). Moreover, cell toxicity in the presence of these enzymes, mediated by apoptosis and driven by a dysregulation of the regulatory proteins $\mathrm{p} 53$ and p21 has also been reported (Huang et al., 2010).

Skin 3D bioprinting is a novel technology which may circumvent several of the problems raised by the use of CEA. The main principle of 3D bioprinting is to generate 3D tissues via the automated deposition of tissue-specific bioinks within biological scaffolds harboring pre-defined shapes. The interaction between cells and bioink' components is crucial to the generation of a harmoniously-organized tissue. Interestingly, recent advances in this field demonstrated that scaffold-free strategies could be 
successfully used to perform 3D bioprinting of human tissues including the skin (Pourchet et al., 2017). In particular, we recently set up a scaffold-free bioprinting procedure for the generation of a fullthickness skin engineered with primary human skin cells. On this basis, we started a long-term project aiming at using the 3D bioprinting technology to treat, in a patient specific way, severe and extended burns without the need of clean-rooms nor long-term cultures. We are then developing an approach of in vivo 3D bioprinting in which an autologous cellularized bioink will be generated from a patient biopsy without any enzymatic digestion and used to bioprint skin cellular constituents directly on the wound. Albanna et al. (Albanna et al., 2019) and Wu et al (Wu, Ravnic, \& Ozbolat, 2020) had noted the effectiveness of such intraoperative approaches.

In our approach, not only the cell extraction from biopsy have to be developed and optimized but also the bioink components, which need to be validated from regulatory and in vivo acceptability point of view. We describe herein the different steps and landmarks of our project and report on our first experimental data obtained from mechanically-extracted human skin cells and clinical grade implantable formulated bioink.

\section{MATERIALS AND METHODS}

\section{Skin tissue procurement}

Keratinocytes and fibroblasts were isolated from normal human skin biopsies obtained from healthy donors with written informed consent. Surgical residues were harvested according to French regulation including declaration to research ministry (DC No. 2008-162). 8 different human skin biopsies ( 6 of abdomen and 2 of arm) were obtained from donors ranging from 36 to 67 years old, with an average age of $50 \pm 14$ years.

\section{Skin cells enzymatic extraction}

Epidermis was separated from dermis using $10 \mathrm{mg} / \mathrm{mL}$ dispase (Life technologies, US). Then epidermal cells were dissociated using trypsin EDTA $0.05 \%$ (Life technologies, US) for $12 \mathrm{~min}$ at $37^{\circ} \mathrm{C}$. Dermal cells were dissociated with collagenase A (Roche Diagnostics) at $0.1 \mathrm{U} / \mathrm{ml}$ for 12 hours at $37^{\circ} \mathrm{C}$. Extracted keratinocytes and fibroblasts were pooled and centrifuged.

\section{Skin cells mechanical extraction}

Skin mechanical dissociation: Mechanical dissociations were performed on skin biopsies cut out as 10 pieces of $4 \mathrm{~mm}$ in diameter, placed in the dissociation tube (gentleMACS C Tubes, 130-093-237, Miltenyi Biotech, Germany) with $1.5 \mathrm{~mL}$ of keratinocyte culture medium containing DMEM and Ham's F12 at a ratio of 3:1 (Life Technologies, France) and supplemented with 10\% Fetal Calf Serum (GE Healthcare HyClone ${ }^{\mathrm{TM}}$, France), $10 \mathrm{ng} / \mathrm{mL}$ epidermal growth factor (EGF) (Austral Biologicals, USA), 24.3 $\mu \mathrm{g} / \mathrm{mL}$ adenine (Sigma-Aldrich, France), $0.4 \mathrm{\mu g} / \mathrm{mL}$ hydrocortisone (Upjohn, Serb Laboratoires, France), $0.12 \mathrm{IU} / \mathrm{mL}$ insulin (Lilly France, France), $2.10^{-9} \mathrm{M}$ triiodo-L-thyronine (Sigma-Aldrich, France), $0.4 \mathrm{\mu g} / \mathrm{mL}$ isoproterenol (Isuprel; Hospira, Netherlands), $20 \mu \mathrm{g} / \mathrm{ml}$ gentamicin (Pantapharm, France), $100 \mathrm{UI} / \mathrm{ml}$ penicillin (Sarbach, France) and $1 \mu \mathrm{g} / \mathrm{ml}$ amphotericin B (Bristol Myers Squibb, France). This medium is the one routinely used for keratinocytes cell-sheet production for severe burnt patient treatment (Auxenfans et al., 2014). The program used was "spleen 1" (56 seconds); 1 to 3 cycles of dissociation were performed. 
Once the dissociator spleen 1 program completed, the obtained micro-explants suspensions were filtered with a $500 \mu \mathrm{m}$ strainer (pluriStrainer $500 \mu \mathrm{m}$, pluriSelect, Germany) and centrifuged 10 minutes at $1200 \mathrm{rpm}$. The obtained microexplant pellets were re-suspended in the above mention culture medium and used for seeding. Micro-explants from 30 biopsies were pooled and seeded in 3.8 $\mathrm{cm}^{2}$ standard cultivation wells. Cells were cultivated on an irradiated feeder layer of human dermal fibroblasts in keratinocyte culture medium at $37^{\circ} \mathrm{C}$ in a $5 \% \mathrm{CO}_{2}$ atmosphere. Cell culture media were changed 3-time a week. Appearance of proliferative keratinocytes and fibroblasts were monitored daily through optical microscopy observations. Since the mechanical extraction only led to microexplants and not single cell suspensions, no further cell characterization through flow cytometry or cell counting were performed.

Fibroblast culture for control experiments: Enzymatically-extracted fibroblasts were isolated from human skin. The biopsies were cut into small pieces. The separation of the epithelium from the dermis was performed with dispase (Gibco), $10 \mathrm{mg} / \mathrm{ml}$ for $3 \mathrm{~h}$ at $4{ }^{\circ} \mathrm{C}$. Then, dermis digestion was performed using collagenase A (Roche Diagnostics), $0.1 \mathrm{U} / \mathrm{ml}$ for $20 \mathrm{~min}$ at $37{ }^{\circ} \mathrm{C}$ with continuous stirring. The digest was purified through a $70 \mu \mathrm{m}$ cell strainer (BD Biosciences). This procedure was repeated six times and the digest was then immediately placed in monolayer culture. Fibroblasts were seeded in Dulbecco's modified eagle's medium (DMEM with glutamax-1, Invitrogen, France) supplemented with $10 \%$ calf serum (HyClone, USA), $20 \mu \mathrm{g} / \mathrm{ml}$ gentamicin (Pantapharm, France), $100 \mathrm{UI} / \mathrm{ml}$ penicillin (Sarbach, France) and $1 \mu \mathrm{g} / \mathrm{ml}$ amphotericin B (Bristol Myers Squibb, France) at a density of 8000 cells $/ \mathrm{cm}^{2}$ in an incubator at $37^{\circ} \mathrm{C}$ in a $5 \% \mathrm{CO}_{2}$ atmosphere. Cell culture media were changed 3 times a week. This cell culture media allows fibroblasts proliferation and not keratinocytes proliferation, leading to fibroblast selective proliferation.

\section{D bioprinting}

Bioink Formulation: R\&D bioink was formulated as a blend of $10 \%(\mathrm{w} / \mathrm{v})$ bovine gelatin (Sigma-Aldrich, France), $0.5 \%(\mathrm{w} / \mathrm{v})$ very low viscosity alginate (Alpha Aesar, France) and $2 \%(\mathrm{w} / \mathrm{v})$ fibrinogen (SigmaAldrich, France) at $37^{\circ} \mathrm{C}$.

For the medical grade bioink, an identical formulation was used which was composed of $10 \%(\mathrm{w} / \mathrm{v})$ medical grade bovine gelatin (optimized by Labskin Creations, France), $1 \%(\mathrm{w} / \mathrm{v})$ medical grade very low viscosity alginate (optimized by Labskin Creations, France) and $2 \%(\mathrm{w} / \mathrm{v})$ medical grade fibrinogen (optimized by Labskin Creations, France) at $37^{\circ} \mathrm{C}$.

Bioprinted dermis: For the preparation of control dermis, enzymatically-extracted fibroblasts were mixed with the bioink at a concentration of $1 \times 10^{6}$ cells. $\mathrm{mL}^{-1}$ and loaded in a $10 \mathrm{~mL}$ syringe. For dermis produced using micro-explants obtained by mechanical dissociation, micro-explants from 120 pieces of $4 \mathrm{~mm}$ in diameter of skin biopsies were seeded in $8 \mathrm{~mL}$ of bioink and loaded in a $10 \mathrm{~mL}$ syringe.

The syringe was equipped with a $0.9 \mathrm{~mm}$ (20 gauges nozzle) diameter extrusion nozzle. Briefly, a custom made bioprinter (LabSkin Creations/TOBECA, France) equipped with a cold building plate $\left(4^{\circ} \mathrm{C}\right)$ and a heating syringe holder $\left(28^{\circ} \mathrm{C}\right)$ was used to deposit $900 \mu \mathrm{m}$ thick layers in a $1 \mathrm{~cm} \times 1 \mathrm{~cm} \times 0.5 \mathrm{~cm}$ $\left(\mathrm{w} x \mid \times \mathrm{h}\right.$ ) format. Once bioprinted, the dermis were incubated for 30 minutes in $\mathrm{CaCl}_{2} 3 \%(\mathrm{w} / \mathrm{v})$ with addition of thrombin $20 \mathrm{U} \cdot \mathrm{mL}^{-1}$ (Sigma- Aldrich, France). These bioprinted dermis were grown at $37^{\circ} \mathrm{C}$ in a $5 \% \mathrm{CO}_{2}$ atmosphere in Dulbecco's modified eagle's medium (DMEM with glutamax-1, Invitrogen, France) supplemented with $10 \%$ calf serum (HyClone, USA), $20 \mu \mathrm{g} / \mathrm{ml}$ gentamicin (Pantapharm, 
France), $100 \mathrm{Ul} / \mathrm{ml}$ penicillin (Sarbach, France) and $1 \mu \mathrm{g} / \mathrm{ml}$ amphotericin B (Bristol Myers Squibb, France).

Cell proliferation assessment: Cell proliferation was measured at day 4, 14, 21 and 28 post bioprinting. Briefly, bioprinted dermis were transferred in a $10 \%(\mathrm{w} / \mathrm{v})$ alamar blue solution (Invitrogen, France) in DMEM, and incubated at $37^{\circ} \mathrm{C}$ and $5 \% \mathrm{CO}_{2}$ for $15-17 \mathrm{~h}$. The coloration changes related to the reduction of resazurin to resorufin by living cells were measured through spectrophotometry at 570 and $600 \mathrm{~nm}$.

Histological analysis: Samples were harvested and fixed in neutral buffered formalin 4\% solution (Alphapath, France) and embedded in paraffin for histological and immunohistological analysis. $5 \mu \mathrm{m}$ thick sections were cut using a Microm HM 520 and stained with haematoxylin-phloxinee-saffron (HPS) for routine histology.

Type I collagen immunostaining: Immunostaining was performed on paraffin-embedded $5 \mu \mathrm{m}$ sections. After dewaxing and rehydration, antigen retrieval was performed according to the manufacturer's instructions and non-specific binding was blocked in PBS containing in addition $4 \%$ of BSA (PBS-BSA 4\%). Sections were incubated overnight at $+4^{\circ} \mathrm{C}$ with monoclonal mouse primary antitype I collagen antibodies (Novotec, France) diluted 100-fold in PBS-BSA 4\% (phosphate buffered saline solution $1 \mathrm{X}$ with addition of $4 \%(\mathrm{w} / \mathrm{v}$ ) bovine serum albumin). Anti-mouse secondary antibodies Alexa 568 conjugated (Life Technologies, France) were diluted 1000-fold in PBS-BSA 4\% and incubated 1 hour at room temperature. Nuclear counterstaining using Hoechst (Thermoscientific, diluted 1000-fold in PBS-BSA 4\%) was carried out. Specimens were visualized using an Observer Z1 optical microscope and images were captured using LSM700 laser scanning confocal system.

Western blotting experiments: Fresh skin fragments of $1 \mathrm{~cm}^{2}$ size were processed either enzymatically or mechanically as described before. The resulting tissue samples were rinsed in cold PBS, centrifuged and immerged in $200 \mu \mathrm{l}$ of RIPA lysis buffer $(20 \mathrm{mM}$ tris-HCl, pH 7.4, $150 \mathrm{mM} \mathrm{NaCl}, 2 \mathrm{mM}$ EDTA, 250 $\mathrm{mM}$ phenylmethylsulfonyl fluoride, $1 \mathrm{mM} \mathrm{N}$-ethylmaleimide, 1\% Nonidet P-40, 1\% TritonX-100, $0.1 \%$ sodiumdeoxycholate, and $0.1 \%$ sodiumdodecyl sulfate [SDS]). Extracts were agitated $18 \mathrm{~h}$ at $4^{\circ} \mathrm{C}$ and RIPA samples were centrifuged. The equivalent amount (10 to $15 \mu$ ) of RIPA extracts supernatants were submitted to electrophoretic migration in $8 \%$ or $4-15 \%$ gradient SDS polyacrylamide gels and western blotting analysis. Rabbit mAb against $B 4$ integrin (EPR8559) was purchased from Abcam (Cambridge, UK), and mouse mAb against B1 integrin (clone HUTS-4) was purchased from MerckMillipore (Saint Quentin en Yvelines, France). The anti-actin pAb was purchased from Sigma (SigmaAldrich, St. Quentin Fallavier, France). The results were analysed using ImageJ software. Data are presented as the means \pm SD, and the Student's t-test (unpaired, two-tailed) was used for two-group comparisons using Prism (GraphPad) software. Three independent skin samples were tested in each condition and the number of repeated experiments is specified ( $n$ ). Individual data values are systematically shown. The significance threshold was set for the $t$-test as $\mathrm{P}<0.05$.

\section{Animal experimentation}

Animals and ethical considerations: All animal procedures were carried out in accordance with the principles of French legislation and the ethic committee for animal experimentation at the CECCAPP, France and after approval by the French Ministry (IBCP-2017-003). 16 male BALB/cnRj-Foxn1 nude mice ( 8 weeks) were purchased from Janvier (LeGenest St Isle, France) and were housed 1 per cage to 
avoid any skin damage, maintained at $21^{\circ} \mathrm{C}$, on a 12 -hour light/dark cycle and with ad Libitum access to normal chow and drinking water.

Thermal burn injury: Mice were anesthetized with an intra-peritoneal injection of ketamine (100 $\mathrm{mg} / \mathrm{kg}$, Imalgene $500^{\circledR}$, Merial, France) and Xylazine (10 mg/kg, Rompun ${ }^{\circledR} 2 \%$, Bayer, France). Subcutaneous analgesic injection of Buprenorphin $\left(0.05 \mathrm{mg} / \mathrm{kg}\right.$, Buprecare ${ }^{\circledR}$, Axience SAS, France) was performed prior and up to three days post-burn for pain management. Animals were checked every day for wound development, clinical signs of pain, distress and morbidity. Body weight was recorded and a loss greater than $20 \%$ of initial weight and/or critical signs of pain or distress (hunched appearance, endless lethargy and immobility) were considered as endpoints and led to animal euthanasia.

Burn wounds were induced using cylindrical brass bars $(8 \mathrm{~mm}$ of diameter, weighing $21.11 \pm 0.04 \mathrm{~g}$; LSPG society, Montbonnot Saint Martin, France) that were heated up to $100^{\circ} \mathrm{C}$ (CHECKTEMP 1, Dominique Dutscher SAS, France, 052026B) in a dry bath (DRYTEMP, Dominique Dutscher SAS, France, 582010) filled with steel beads (Dominique Dutscher SAS, France, 582001) and applied for 5 seconds on the skin on the upper part of the back. At D4 post-burn, under ketamine $(100 \mathrm{mg} / \mathrm{kg}$, Imalgene $500^{\circledR}$, Merial, France) for anesthesia and Xylazine (10 mg/kg, Rompun ${ }^{\circledR} 2 \%$, Bayer, France) for analgesia, a surgical debridement of the wound was performed with a microsurgical knife (Microsurgical Knife, 15ㅇ, 3 mm blade, 13.5, 500249, World Precision Instruments, Sarasota, FL). Mice were kept on a temperature controlled heating mat until they fully recovered from anesthesia.

The entire wound area was covered with a sterile transparent dressing (Tegaderm ${ }^{\mathrm{TM}}$, Nexcare, 3M Health Care, St. Paul, MN).

Bioink Toxicity test: In order to test the biocompatibility of the bioink on the skin, $50 \mu \mathrm{L}$ of the medical grade bioink (without cells) were deposited on each burned wound after debridement and $50 \mu$ l of the medical grade bioink (without cells) were injected subcutaneously on the flank of the mouse. The objective was here to verify the in vivo tolerance of the cell-free bioink and not the efficiency of the cellularized one.

Wound area assessment: The wounds were imaged at the day of wound debridement and at day 7 (Pentax digital camera K-r with a Pentax 100 Macro WR lens, C.R. Kennedy \& Co. ,Victoria, Australia) and the extent of wound size was estimated using image analysis software (ImageJ, National Institutes of Health, Bethesda, MD).

For healing assessment, pictures of each wound were blindly analyzed by two plastic surgeons on 5 evaluation criteria: the tissue retraction, the presence or not of a discharge linked to an infection, the presence of an inflammatory halo, the presence of a bead of epidermisation and the presence of a central epidermisation.

Assessment of skin perfusion: A laser Doppler speckle (PERICAM, Perimed) was used to measure skin perfusion at two sites: wounded skin and the non-wounded skin at day 1, 3, 5 and 7 post-treatment with bioink. The skin temperature (Bat-12 Physiomed) on each site was also recorded.

Skin biopsies: At day 7 post-treatment with bioink, all mice were euthanized by intraperitoneal injection of an overdose of sodium pentobarbital $(60 \mathrm{mg} / \mathrm{kg}$, Ceva santé animale SA, la ballastiere, 
France). For each mouse, skin samples of each skin experiment sites were harvested and treated for histological analysis.

\section{RESULTS}

The primary aim of the present study is to bring an innovative approach in the field of severe burn treatment through the concept of in vivo dermis bioprinting in which an autologous cellularized bioink is generated from a patient biopsy without any enzymatic digestion and used to bioprint skin cellular constituents directly on the wound. This type of approach having proven its effectiveness through the work of Albanna et al. (Albanna et al., 2019).

In this concept, different incremental developments shall be performed including cell mechanical extraction from patient biopsy and bioink components validation from regulatory and in vivo acceptability point of view.

\section{Mechanical extraction}

The first step of the present study was to define an enzyme-free extraction protocol allowing to obtain viable and proliferative keratinocytes and fibroblasts. In the previously published study by He et $a l$. (He, de Oliveira, Keijsers, Joosten, \& Koenen, 2016), extraction of lymphocytes from the skin was successfully performed using the present GentleMACS Dissociator ${ }^{\mathrm{TM}}$ apparatus (spleen 1 program) but in combination with the use of collagenase. In the present case, since our postulate was to avoid any enzymatic reaction, the "spleen 1" program was launched several times in order to compensate the lack of enzymatic activity.

Table 1 presents the evolution of the average time to onset proliferative keratinocytes and fibroblasts detection in 2D cultures started from cell extraction using 1, 2 and 3 cycles of dissociation by GentleMACS Dissociator $^{\mathrm{Tm}}$. The time to onset of proliferation was determined on the basis of the identification of the first adherent cells coming from micro-explants (see Supplementary Information 1). The obtained duration is the mean value of 3 different donors.

\section{Table 1}

As a matter of fact, mechanical dissociation using only one cycle was the most efficient for fibroblasts forthcoming development in 2D. Indeed, the first proliferative fibroblasts were observed after 10 days of culture. The situation was found to be slightly different for the keratinocytes, for whom the first proliferative cells were visible after only 6 days of culture and never later than the $8^{\text {th }}$ day. A single cycle was therefore selected since this condition allows the concomitant appearance of proliferative keratinocytes and fibroblasts within 10 days. Looking now at the standard deviations obtained, i.e. the variability of the time to onset proliferative cells between donors, no significant difference between the donors was observed (standard deviation between $5 \%$ and $16 \%$ ).

Once the possibility to obtain proliferative keratinocytes and fibroblasts validated, the next step was to evaluate proliferation rate of each cell type from the dissociated biopsy. Here, the confluency percentage of the culture plate for each cell type was used as indicator. Table 2 presents the evaluation 
of the area occupied by the different cell types after 21 days of culture of 3 biopsies extracted using 1 , 2 or 3 "spleen1" dissociation cycles.

\section{Table 2}

As observed previously, 1 dissociation cycle appeared to be the optimum condition since at day 21 after extraction, a $100 \%$ confluency was obtained with an equilibrium between keratinocytes and fibroblasts content (30-40\% and 60-70\%, respectively).

Interestingly, increasing the number of dissociation cycles has two deleterious effects: lowering drastically the fibroblasts proliferation capacity and bringing variation between the different sources of biopsy (see keratinocyte with 3 cycles for example).

The selected protocol was then validated on a larger panel of 8 donors with average age of 50 years (min: 36, max: 67). Once again, the proliferative keratinocytes were observed after an average period of 5.9 days +/- 1.2 and proliferative fibroblasts after an average period of 8.9 days +/- 0.8 . Reproducibility and robustness of the protocol were then validated.

Finally, this mechanical extraction protocol allows the preservation of the expression of the two main integrins involved in skin cell adhesion processes, namely beta $1(\beta 1)$ and beta 4 ( $\beta 4$ ) integrins, compared to enzymatic extraction (Figure 1). Our western blotting experiments revealed that not only both $\beta 1$ and $\beta 4$ integrin subunits are expressed in the mechanically derived extracts, but their expression is significantly higher than those detected in the enzymatically derived extracts. As previously documented (Kallas-Kivi et al., 2018) expression of the integrin B1 is highly affected by trypsin treatment, and we report here that the $B 4$ integrin is affected as well, but to much a lesser extent. These results show that the absence of enzymatic treatment is beneficial for the preservation of the integrin pool of skin cells.

Therefore, the mechanical extraction protocol described here allows to obtain skin cells expressing an intact pool of integrins.

\section{Figure 1}

\section{Dermis 3D bioprinting using mechanically extracted cells}

Pourchet et al. (Pourchet et al., 2017) has demonstrated the feasibility of the production of human dermis through the 3D bioprinting of human primary dermal fibroblasts seeded in a specially designed bioink. In the present study, it was then important to estimate the proliferation of the mechanically extracted cells, compare them to enzymatically-extracted fibroblast proliferation and validate that the extracted cells reached a cell density suitable for tissue development (extracellular matrix production).

Figure 2

Figure 2 presents the cellular activity of the 3D bioprinted dermis produced using both mechanically extracted cells and enzymatically-extracted fibroblasts. For both conditions, the alamar blue analysis indicates an increase in cell activity, directly related to the cell density in the bioprinted tissue, between D7 and D28. Nevertheless, a clear impact of the cell extraction method was identified with a 14 days 
of proliferation delay for the mechanically extracted cells. This delay shall be correlated to the mean necessary time to get onset of proliferative fibroblasts (Table 1) in 2D culture, right after extraction where a similar $10+/-1.2$ days period was identified. Finally, despite this proliferation discrepancy, the experienced delay was found to be almost overtaken at day 28 post 3D bioprinting.

After 6 weeks of maturation, the 3D bioprinted dermis were analyzed through histology and immunofluorescence to study the cell distribution and the extra-cellular matrix production, respectively.

\section{Figure 3}

Histological analysis confirmed the presence of cells in all 3D bioprinted dermis (Figure 3-A and B) and the presence of a neosynthesized extracellular matrix in the tissue surrounding the cells. However, the extracellular matrix produced by the mechanically extracted cells was shown to exhibit a less homogeneous distribution. Immunolabelling of type I collagen finally confirmed that both 3D bioprinted dermis had secreted an extra cellular matrix composed of at least type I collagen, the major component of the dermis ECM (Figure 3-D and E, Supplementary information 2).

In order to identify the cell types present in the dermis bioprinted using mechanically extracted cells, additional immunolabelling of human Vimentin and Pancytokeratin were performed. These labelling were used to localize fibroblasts and keratinocytes, respectively. Indeed, since the mechanical extraction leads to the isolation of fibroblast and keratinocyte clones, it is possible that both cells proliferate in the bioprinted dermis. Supplementary information $\mathbf{3}$ and $\mathbf{4}$ depict the obtained results. As can be seen, Vimentin presence was clearly demonstrated with a strong labelling after 5 weeks of maturation. On the contrary, Pancytokeratin wasn't found in any of the bioprinted dermis, even after 6 weeks of culture. These results are easily explained by the fact that keratinocytes are not able to proliferate in a 3D environment and need an air-liquid interface to multiply (Asselineau, Bernhard, Bailly, \& Darmon, 1985; Black et al., 2005). This non-proliferation of keratinocytes within the bioprinted dermis was also demonstrated using by the bioprinting of a bioink seeded with both enzymatically extracted (purified) keratinocytes and fibroblasts. Here again, it was clearly show that Vimentin was easily identified in the dermis after 5 weeks while no Pancytokeratin can be found, proof of the absence of detectable keratinocytes within the tissue (Supplementary information 4).

\section{From R\&D to medical grade bioink}

Since the final objective of the present development is the in vivo 3D bioprinting of skin in human, all the components of the bioink shall be validated for clinical applications. From our previous study (Pourchet et al., 2017), the composition and proportions of the bioink have been optimized, but only with $R \& D$, non-medical grade material. We are then presenting herein the development, selection and validation of medical grade bioink components.

Three sterile and GMP manufactured gelatin powders (from 3 different manufacturers) were selected according to their high bloom indices. The bloom index indicates gel resistance to sinking. The gelatin must have a bloom index allowing both bioprinting and the achievement of a compact dermis. Two low viscosity alginate powders from two different manufacturers were tested. Two fibrinogens sources, parts of the composition of two drugs, were also selected (Table 3). These components were first replaced one by one in the R\&D bioink and the obtained dermis studied according to 
enzymatically-extracted fibroblast growth rate (alamar blue experiment) during a 4 weeks follow-up after 3D bioprinting. The growth indicator was here $\mathrm{OD}_{570}-\mathrm{OD}_{600}$ of at least 2.8 at $\mathrm{D} 28$.

\section{Table 3}

Out of the seven components tested, only the 3 LabSkin Creations optimized gelatin, alginate and fibrinogen were able to produce printable bioink leading to the growth of the enzymatically-extracted fibroblasts after 28 days of culture. Within the LabSkin Creations optimized gelatins, a high bloom index (280) was selected for the final bioink composition in order to obtain the best bioink rheological properties.

Figure 4 presents the comparison of the enzymatically-extracted fibroblasts proliferation in the medical grade bioink and in the former R\&D bioink. As a matter of fact, no significant differences were observed at D7, D14 and D21 between the medical grade bioink and the R\&D bioink. The kinetic and level of activity were thus found to be identical.

Once again, in order to fully characterize the dermis production using enzymatically-extracted fibroblasts and the newly formulated bioink, the 3D bioprinted dermis were analyzed after 6 weeks of maturation through histology and immunofluorescence to evaluate the cell distribution and the extracellular matrix production, respectively. Histological analysis confirmed the presence of cells in all 3D bioprinted dermis (Figure 3-A and C) and the presence of a neosynthesized extracellular matrix around the cells. Immunolabelling of type I collagen finally confirmed that both 3D bioprinted dermis had secreted an extra cellular matrix composed of at least type I collagen, the major component of the ECM of the dermis (Figure 3-D and F).

Here again, Vimentin and Pancytokeratin labelling were used to detect fibroblast and keratinocyte, respectively. One more time, just like for the R\&D bioink, no keratinocyte were identified within the bioprinted dermis after 5 or 6 weeks of maturation (Supplementary information 3, 4 and 5).

\section{Figure 4}

Since the final goal of the present development is the formulation of a medical grade bioink seeded with mechanically extracted skin cells, the bioprinted cells' proliferation and type I collagen production were characterized within dermis produced using extracted cell and medical grade bioink. Figure $\mathbf{5}$ presents the mechanically extracted cells development within the medical grade bioprinted dermis. One more time, as observed using the R\&D bioink (Figure 2), the proliferation of mechanicallyextracted cells experienced a 2 weeks delay when compared to the enzymatically-extracted fibroblasts in the medical grade bioink. Nevertheless, after 5 weeks of culture, the histological and immunofluorescence experiments clearly demonstrated the presence of cells and newly synthesized type I collagen within the 3D bioprinted dermis (Figure 6). It is also worth to mention that a clear difference between enzymatically and mechanically extracted cells was observed, mainly according to the cell density. This observation is consistent with the delay in proliferation observed at D35, i.e. 5 weeks of culture (Figure 5).

\section{Figure 5}

\section{Figure 6}




\section{In vivo tolerance study of medical grade bioink}

In order to fully validate the feasibility of the in vivo use of our newly formulated medical grade bioink, series of experiments were performed on mice. Bioink was tested in two different ways, either injected subcutaneously in order to identify any inflammatory effects, or on a controlled deep second degree burn model in order to identify any effects of the bioink on healing. In every case, blood perfusion measurements, temperature measurements, macroscopic observations and histological analysis were performed. The perfusion and temperature measurements did not enable the identification of any significant effect of the bioink (Supplementary information 6), proof of the absence of inflammation related to the presence of the bioink. Form the macroscopic observation of the subcutaneous injection sites, no effect of the injection was observed either and the medical grade bioink was degraded without any noticeable visible surface reaction (Supplementary information 7). From the observation of the bioink covered wounds (Figure 7-A), no infection or purulent discharge was observed. A heterogeneous fibrinous aspect within the wound group was observed but no inflammatory bead was evidenced showing the absence of perilesional inflammatory reaction. The only difference between bioink covered wound and untreated wound was the presence of more shrinkage folds in the control group (mean retraction score of 2 in the control group vs 0.8 in the bioink covered group), which is associated with a higher risk of dysfunctional retractile scar formation.

From the histological analysis performed at different steps of the experiment, numerous conclusions can also be made.

First, a clear difference between the normal mouse skin (Figure 7-B) and the created deep second degree burn model before debridement (Figure 7-C) was observed. Particularly, the burn model presents a deterioration of the epidermis and of a significant part of the dermis, with the presence of necrotic tissue and the absence of hair follicles. These features correspond well to a deep second degree burn model. At day 7 after debridement, the wounds of the control group (Figure 7-D) and of the bioink covered group (Figure 7-E) were found to be closed with a reconstituted epidermis. Also, all the necrotic tissues have been eliminated and a filling tissue has been formed to fill in the loss of substance caused by the burn. Compared to a normal mouse epidermis (Figure 7-B), the newly formed epidermis is thickened and the underlying dermis contains a very dense and highly cellularized collagen fiber network, which corresponds to the end of the proliferative phase observed physiologically during healing and announcing the start of the tissue remodeling.

\section{Figure 7}

\section{Discussion}

Our study describes the development of a mechanical extraction method for skin cells, without any additional enzymatic digestion step. These extracted cells can then be 3D bioprinted in a medical bioink implantable in humans. The preclinical tolerance study of this medical bioink did not show any sign of inflammation on the deep second-degree burnt mouse and is therefore well tolerated. This method could thus be compatible with a direct use in an operating theatre for the treatment of deep second degree burn patients. 
We encountered difficulties to compare our result with other - few papers being published on skin cells mechanical extraction. Usually, when mechanical dissociation is involved in cell preparation from tissue, it is combined with an enzymatic digestion (He et al., 2016) and most of the time, enzyme digestion alone is use to obtain autologous cell suspensions (Kadam, 2016; van Geel, Goh, Wallaeys, De Keyser, \& Lambert, 2011). For example, ReCell technique - a nonamplified cell suspension obtain with trypsin - is routinely used to treat wound (De Angelis, Migner, Lucarini, Agovino, \& Cervelli, 2015) or vitiligo with a melanocytes enriched cell suspension (Kadam, 2016). Yoon et al (Yoon et al., 2017). This technique enable the production of an autologous skin cell suspension in order to improve wound healing. This method resulted in a cell suspension composed mainly of keratinocytes, subsequently used to promote wound closure, but not dermis reconstruction. On the contrary, our protocol was proven to enable the achievement of proliferative keratinocytes and fibroblasts, mainly thanks to the use $2 \mathrm{D}$ culture on irradiated fibroblast feed layers. Indeed, others culture supports have been tested (plastic support with or without type I collagen coating - data not shown) which did not permitted the culture of either keratinocytes or fibroblasts (Daniels, Kearney, \& Ingham, 1997; He et al., 2016). The irradiated fibroblasts were then proven to constitute a suitable support for fibroblasts and keratinocytes culture from dissociated skin micro-explants.

With the present method, we have been able to observe micro-explants of skin obtained after a dissociation cycle of 56 seconds. These micro-explants were shown to adhere to the feeder layer and to generate proliferative keratinocytes and fibroblasts in 2D cell cultures. This technique is closed to the Meek's technique which allows skin grafting mincing and expansion up to 10-time to overcome the lack of healthy skin available (Meek, 1958, 1963). This technique has been modified since, but the principle of peripheral expansion of the borders remains the same, where the keratinocytes will start their expansion from these borders of the micrografts to re-epithelialize the wound (Hersel, Dahmen, \& Kessler, 2003; Meek, 1958, 1963). Our technique has the advantage of having explants of much smaller size, and therefore potentially a greater number of keratinocytes and fibroblasts which can be extracted and multiply to have a larger grafted surface in the end. Other extraction conditions were tested: shorter programs of GentleMACS Dissociator ${ }^{\mathrm{TM}}$ or fractioned dissociation by removing the cell suspension obtained before relaunching a new dissociation cycle with the same biopsy, but all the results showed that only one launch of the spleen cycle 1 was the best solution for obtaining equilibrated fibroblast and keratinocyte cell populations.

Obtaining these micro-explants, and not perfectly separated cell populations, may explain the growth delay visualized after 3D bioprinting of the extracted cells compared to the enzymaticallyextracted fibroblasts. The two weeks delay observed can be explained by the time taken by cells to exit their native microenvironment and to colonize the 3D microenvironment. This delay corresponds to $2 \mathrm{D}$ culture observations in which the first proliferative keratinocytes appeared after 8 days and those of fibroblasts after 10 days of cultures.

We have also shown that the cells extracted using the GentleMacs Dissociator were compatible with a 3D bioprinting technique. Using the developed protocol, the extraction of 120 punch biopsies with a diameter of $4 \mathrm{~mm}$ from a defatted solid skin $\left(15 \mathrm{~cm}^{2}\right)$, theoretically enables the 3D bioprinting of $80 \mathrm{~cm}^{2}$ tissue of $900 \mu \mathrm{m}$ thickness. This $1 / 5$ surface ratio is close to the one obtained 
with the "mesh technique" in which a sample of healthy thin skin is excised and chewed. Our technique must therefore be further optimized in order to increase the multiplication ratio of the 3D bioprinted surface. To do this, several tracks are envisioned, the 3D bioprinting of a smaller number of punch biopsies will have to be studied, as well as the composition of the bioink. Indeed, cell anchoring domains must be present within the components of the bioink in order to offer a microenvironment compatible with cell proliferation. An example is the RGD sequence on which cell are anchoring and develop basal functions that help control their development with the production of signalling molecules (Hersel et al., 2003). Human fibrinogen used in medical bioink is less rich in RGD than bovine fibrinogen. A new bioink enriched in fibrinogen shall then be tested in a near future with a higher proportion of human fibrinogen, in order to accelerate the migration of the extracted cells from the micro-explants. In addition, the thickness of the bioprinting could be reduced in order to have a layer not exceeding $400 \mu \mathrm{m}$ thick and allow rapid microvascularization of the newly formed tissue (Tran \& Wen, 2014).

Finally, the safety of this medical bioink has been proven by its application on second degree thermal burns on a murine model through monitoring of specific inflammation parameters. A common inflammatory reaction is usually accompanied by the appearance of local and diffuse redness, a feeling of warmth and an increase in angiogenesis and therefore in blood flow. None of these indicators were observed macroscopically or measured at the wound. It was even proposed that in view of the less retracted aspect of the wound, the application of bioink could promote healing by re-epidermization and formation of a filling tissue (Clark, Ghosh, \& Tonnesen, 2007).

To conclude, the present study brings an innovative approach in the field of severe burn treatment through the concept of in vivo dermis 3D bioprinting in which an autologous cellularized bioink is generated from a patient biopsy without any enzymatic digestion and used to 3D bioprint skin cellular constituents directly on the wound.

\section{ACKNOWLEDGEMENTS}

« This work was (partially) supported by the French ANR program ASTRID (project BLOC-PRINT ANR-16-ASTR-0021), led and funded by the Direction Générale de l'Armement (DGA) and by the Rhône-Alpes Pack-Ambition project 3D-healing ".

We thank the local animal care facility (LBTI UMR CNRS 5305, Lyon) and Dominique SigaudoRoussel for technical assistance on animal model and care. 


\section{REFERENCES}

Albanna, M., Binder, K. W., Murphy, S. V., Kim, J., Qasem, S. A., Zhao, W. X., .. Yoo, J. J. (2019). In Situ Bioprinting of Autologous Skin Cells Accelerates Wound Healing of Extensive Excisional Full-Thickness Wounds. Scientific Reports, 9. doi:Artn 1856

\subsection{8/S41598-018-38366-W}

Asselineau, D., Bernhard, B., Bailly, C., \& Darmon, M. (1985). Epidermal Morphogenesis and Induction of the 67-Kd Keratin Polypeptide by Culture of Human Keratinocytes at the Liquid Air Interface. Experimental Cell Research, 159(2), 536-539. doi:Doi 10.1016/S00144827(85)80027-6

Autengruber, A., Gereke, M., Hansen, G., Hennig, C., \& Bruder, D. (2012). Impact of enzymatic tissue disintegration on the level of surface molecule expression and immune cell function. Eur $J$ Microbiol Immunol (Bp), 2(2), 112-120. doi:10.1556/EuJMI.2.2012.2.3

Auxenfans, C., Menet, V., Catherine, Z., Shipkov, H., Lacroix, P., Bertin-Maghit, M., . . Braye, F. (2015). Cultured autologous keratinocytes in the treatment of large and deep burns: A retrospective study over 15 years. Burns, 41(1), 71-79. doi:10.1016/j.burns.2014.05.019

Auxenfans, C., Shipkov, H., Bach, C., Catherine, Z., Lacroix, P., Bertin-Maghit, M., . . Braye, F. (2014). Cultured allogenic keratinocytes for extensive burns: A retrospective study over 15 years. Burns, 4O(1), 82-88. doi:10.1016/j.burns.2013.05.005

Black, A. F., Bouez, C., Perrier, E., Schlotmann, K., Chapuis, F., \& Damour, O. (2005). Optimization and characterization of an engineered human skin equivalent. Tissue Engineering, 11(5-6), 723733. doi:10.1089/ten.2005.11.723

Chester, A. L., Balderson, D. S., \& Papini, R. P. G. (2004). A review of keratinocyte delivery to the wound bed. Journal of Burn Care \& Rehabilitation, 25(3), 266-275. doi:10.1097/01.Bcr.0000124749.85552.Cd

Clark, R. A. F., Ghosh, K., \& Tonnesen, M. G. (2007). Tissue engineering for cutaneous wounds. Journal of Investigative Dermatology, 127(5), 1018-1029. doi:10.1038/sj.jid.5700715

Daniels, J. T., Kearney, J. N., \& Ingham, E. (1997). An investigation into the potential of extracellular matrix factors for attachment and proliferation of human keratinocytes on skin substitutes. Burns, 23(1), 26-31. doi:Doi 10.1016/S0305-4179(96)00061-7

De Angelis, B., Migner, A., Lucarini, L., Agovino, A., \& Cervelli, V. (2015). The use of a non-cultured autologous cell suspension to repair chronic ulcers. International Wound Journal, 12(1), 3239. doi:10.1111/iwj.12047

Echinard, C. (1998). Under the epidermis, the dermis, or how to interpret skin cultures? Ann Chir Plast Esthet, 43(2), 197-205.

Ehrenreich, M., \& Ruszczak, Z. (2006). Tissue-engineered temporary wound coverings. Important options for the clinician. Acta Dermatovenerol Alp Pannonica Adriat, 15(1), 5-13.

Evers, L. H., Bhavsar, D., \& Mailander, P. (2010). The biology of burn injury. Experimental Dermatology, 19(9), 777-783. doi:10.1111/j.1600-0625.2010.01105.x

He, X. H., de Oliveira, V. L., Keijsers, R., Joosten, I., \& Koenen, H. J. P. N. (2016). Lymphocyte Isolation from Human Skin for Phenotypic Analysis and Ex Vivo Cell Culture. Jove-Journal of Visualized Experiments(110). doi:ARTN e52564

$10.3791 / 52564$

Hersel, U., Dahmen, C., \& Kessler, H. (2003). RGD modified polymers: biomaterials for stimulated cell adhesion and beyond. Biomaterials, 24(24), 4385-4415. doi:10.1016/s0142-9612(03)00343-0

Huang, H. L., Hsing, H. W., Lai, T. C., Chen, Y. W., Lee, T. R., Chan, H. T., . . Chan, H. L. (2010). Trypsininduced proteome alteration during cell subculture in mammalian cells. Journal of Biomedical Science, 17. doi:Artn 36 
10.1186/1423-0127-17-36

Kadam, D. (2016). Novel expansion techniques for skin grafts. Indian J Plast Surg, 49(1), 5-15. doi:10.4103/0970-0358.182253

Kallas-Kivi, A., Trei, A., Stepanjuk, A., Ruisu, K., Kask, K., Pooga, M., \& Maimets, T. (2018). The role of integrin $\beta 1$ in the heterogeneity of human embryonic stem cells culture. Biol Open, 7(11). doi:10.1242/bio.034355

Meek, C. P. (1958). Successful Microdermagrafting Using the Meek-Wall Microdermatome. American Journal of Surgery, 96(4), 557-558. doi:Doi 10.1016/0002-9610(58)90975-9

Meek, C. P. (1963). Extensive severe burn treated with enzymatic debridement and microdermagrafting: case report. Am Surg, 29, 61-64.

Pourchet, L. J., Thepot, A., Albouy, M., Courtial, E. J., Boher, A., Blum, L. J., \& Marquette, C. A. (2017). Human Skin 3D Bioprinting Using Scaffold-Free Approach. Advanced Healthcare Materials, 6(4). doi:Artn 1601101

10.1002/Adhm.201601101

Rousselle, P., Braye, F., \& Dayan, G. (2019). Re-epithelialization of adult skin wounds: Cellular mechanisms and therapeutic strategies. Advanced Drug Delivery Reviews, 146, 344-365. doi:https://doi.org/10.1016/j.addr.2018.06.019

Rowan, M. P., Cancio, L. C., Elster, E. A., Burmeister, D. M., Rose, L. F., Natesan, S., . . Chung, K. K. (2015). Burn wound healing and treatment: review and advancements. Critical Care, 19. doi:10.1186/s13054-015-0961-2

Tran, V., \& Wen, X. (2014). 4 - Rapid prototyping technologies for tissue regeneration. In R. Narayan (Ed.), Rapid Prototyping of Biomaterials (pp. 97-155): Woodhead Publishing.

van Geel, N., Goh, B. K., Wallaeys, E., De Keyser, S., \& Lambert, J. (2011). A Review of Non-cultured Epidermal Cellular Grafting in Vitiligo. J Cutan Aesthet Surg, 4(1), 17-22. doi:10.4103/09742077.79181

Varkey, M., Ding, J., \& Tredget, E. E. (2015). Advances in Skin Substitutes-Potential of Tissue Engineered Skin for Facilitating Anti-Fibrotic Healing. Journal of Functional Biomaterials, 6(3), 547-563. doi:10.3390/jfb6030547

Wu, Y., Ravnic, D. J., \& Ozbolat, I. T. (2020). Intraoperative Bioprinting: Repairing Tissues and Organs in a Surgical Setting. Trends in Biotechnology. doi:https://doi.org/10.1016/j.tibtech.2020.01.004

Yoon, C., Lee, J., Jeong, H., Lee, S., Sohn, T., \& Chung, S. (2017). Rapid preparation of a noncultured skin cell suspension that promotes wound healing. Cell and Tissue Banking, 18(2), 131-141. doi:10.1007/s10561-017-9615-8 
Table 1: Average day of onset from which proliferative keratinocytes (Kc) and fibroblasts (Fb) are observed in the culture wells after seeding the products of the mechanical extraction according to the launch number of the "spleen 1" program: 1-time, 2-time or 3-time. Mean value and standard deviation for 3 different donors.

\begin{tabular}{|c|c|c|}
\hline Number of cycle of "spleen 1" & $\begin{array}{l}\text { Kc growth observed from day } \\
\text { (Mean +/- standard deviation) }\end{array}$ & $\begin{array}{c}\text { Fb growth observed from day } \\
\text { (Mean +/- standard deviation) }\end{array}$ \\
\hline 1 & $\mathrm{D} 8+/-0.5$ & $\mathrm{D} 10+/-1.2$ \\
\hline 2 & $\mathrm{D} 6+/-0.3$ & $\mathrm{D} 19+/-0.8$ \\
\hline 3 & $\mathrm{D} 8+/-1.3$ & $\mathrm{D} 21+/-2$ \\
\hline
\end{tabular}

Table 2: Evaluation of the confluency percentage of proliferative keratinocytes $(\mathrm{Kc})$ and fibroblasts (Fb) in culture wells at D21 according to the launch number of the "spleen 1" program: 1-time, 2-time or 3-time.

\begin{tabular}{|c|c|c|c|c|c|c|}
\hline $\begin{array}{c}\text { Number of cycle of } \\
\text { "spleen 1" }\end{array}$ & \multicolumn{2}{|c|}{$\mathbf{2}$} & \multicolumn{2}{c|}{3} \\
\hline & & Ko & Kc & Fb & Kc & Fb \\
\hline & Kc & Fb & $25-35 \%$ & $2 \%$ & $2-5 \%$ & $5 \%$ \\
\hline Abdomen (59 Y) & $30-40 \%$ & $60-70 \%$ & $40-50 \%$ & $5-10 \%$ & $40-50 \%$ & $5-10 \%$ \\
\hline Abdomen (47 Y) & $30-40 \%$ & $60-70 \%$ & $40 \%-50 \%$ & $5-10 \%$ & $5-10 \%$ & $5-10 \%$ \\
\hline Abdomen (56 Y) & $30-40 \%$ & $60-70 \%$ & $40-50 \%$ \\
\hline
\end{tabular}

Table 3: Presentation of the tested components. Component validation was based on enzymatically-extracted fibroblast growth in 3D bioprinted dermis.

\begin{tabular}{|c|c|c|}
\hline$R \& D$ component & Medical GMP component & Cell growth after 3D bioprinting \\
\hline \multicolumn{3}{|c|}{ Gelatin : protein derived from collagen of animal origin } \\
\hline \multirow{3}{*}{$\begin{array}{c}\text { Pig skin gelatin } \\
\text { Powder } \\
\text { Bloom index }=300 \\
\text { Type A } \\
\text { For cell culture }\end{array}$} & LabSkin Creations optimized gelatin & Validated \\
\hline & $\begin{array}{l}\text { Nitta Gelatin Inc }{ }^{\circledast} \\
\text { Bloom index } 80-120\end{array}$ & Does not hold, melts at D4 \\
\hline & Cutanplast Brunelli® & Insoluble hemostatic gelatin \\
\hline \multicolumn{3}{|c|}{ Alginate: polysaccharide biopolymer } \\
\hline \multirow{2}{*}{$\begin{array}{l}\text { Alginic acid sodium salt } \\
\text { Poudre } \\
\text { Very low viscosity }=100-300 \mathrm{mPa}^{*} \mathrm{~s}\end{array}$} & Novamatrix $^{\circledast}: 100-300 \mathrm{mPa}^{*} \mathrm{~s}$ & No cell growth \\
\hline & LabSkin Creations optimized gelatin & validated \\
\hline \multicolumn{3}{|c|}{ Fibrinogen: coagulation protein } \\
\hline \multirow[t]{2}{*}{$\begin{array}{c}\text { From Type I-S bovine plasma } \\
\text { Powder } \\
\text { Coagulable protein level: } 65-85 \%\end{array}$} & $\begin{array}{c}\text { Clottafact }^{\circledR}: \\
\text { Human fibrinogen } \\
1.5 \mathrm{~g} / 100 \mathrm{ml}\end{array}$ & No cell growth \\
\hline & LabSkin Creations optimized gelatin & validated \\
\hline
\end{tabular}




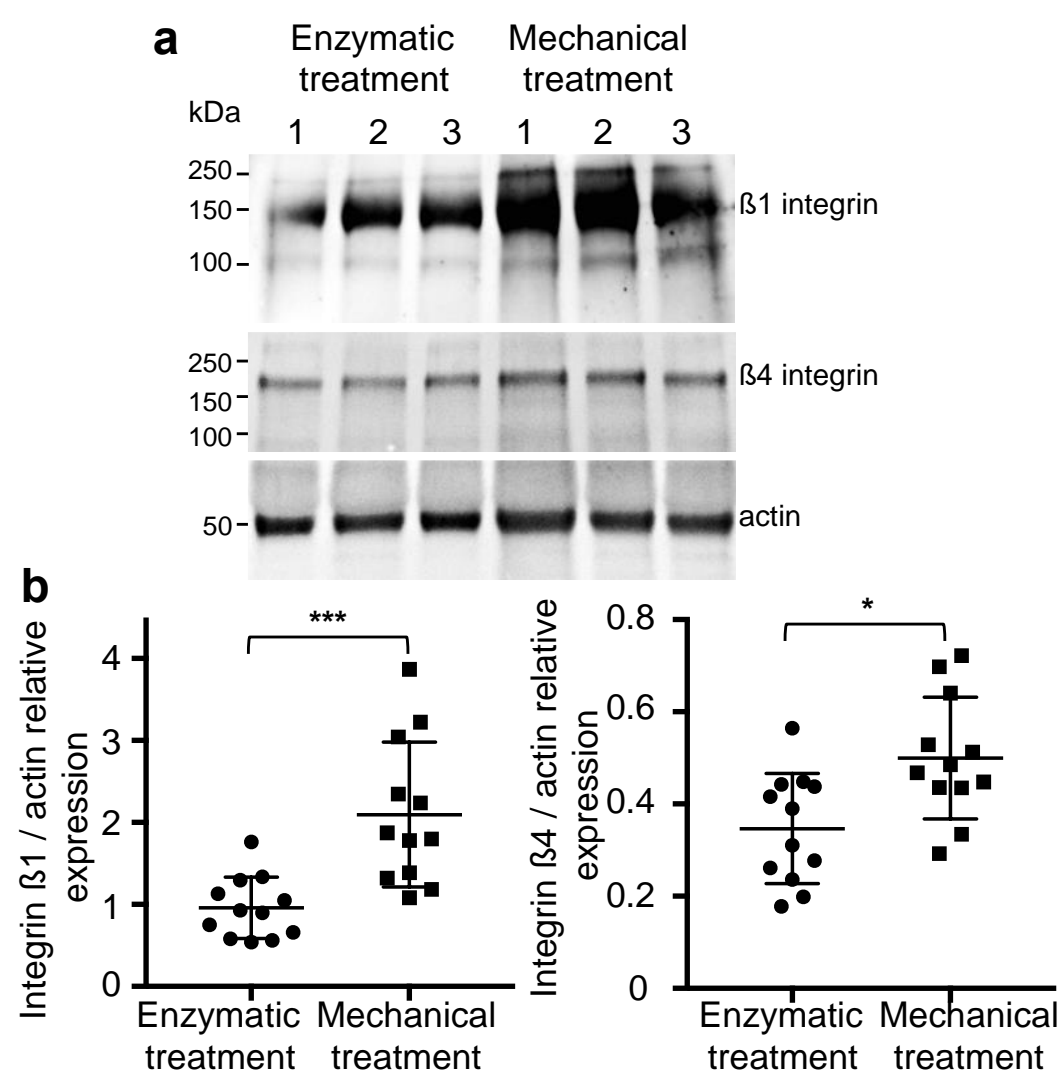

Figure 1: (a) RIPA sample extracts of 3 independent skin biopsies (labelled 1, 2, 3) obtained from enzymatic or mechanical dissociation were resolved in a $8 \%$ gel in non-reducing conditions (for $\beta 1$ integrin) and in a 4-15\% gradient gel in reducing conditions (for $\beta 4$ integrin and actin), and were transferred to nitrocellulose membranes. Western blotting of $\beta 1$ integrin, $\beta 4$ integrin and actin are shown. (b) $\beta 1$ and $\beta 4$ integrin relative expression to actin used as a loading control. Each scatter plot includes measures of $n=12$ independent experiments. ${ }^{* *} p<0.0005,{ }^{*} p<0.02$ vs. control, Student's t-test. (a) Position of molecular weight markers is shown on the left of western blotting images. 


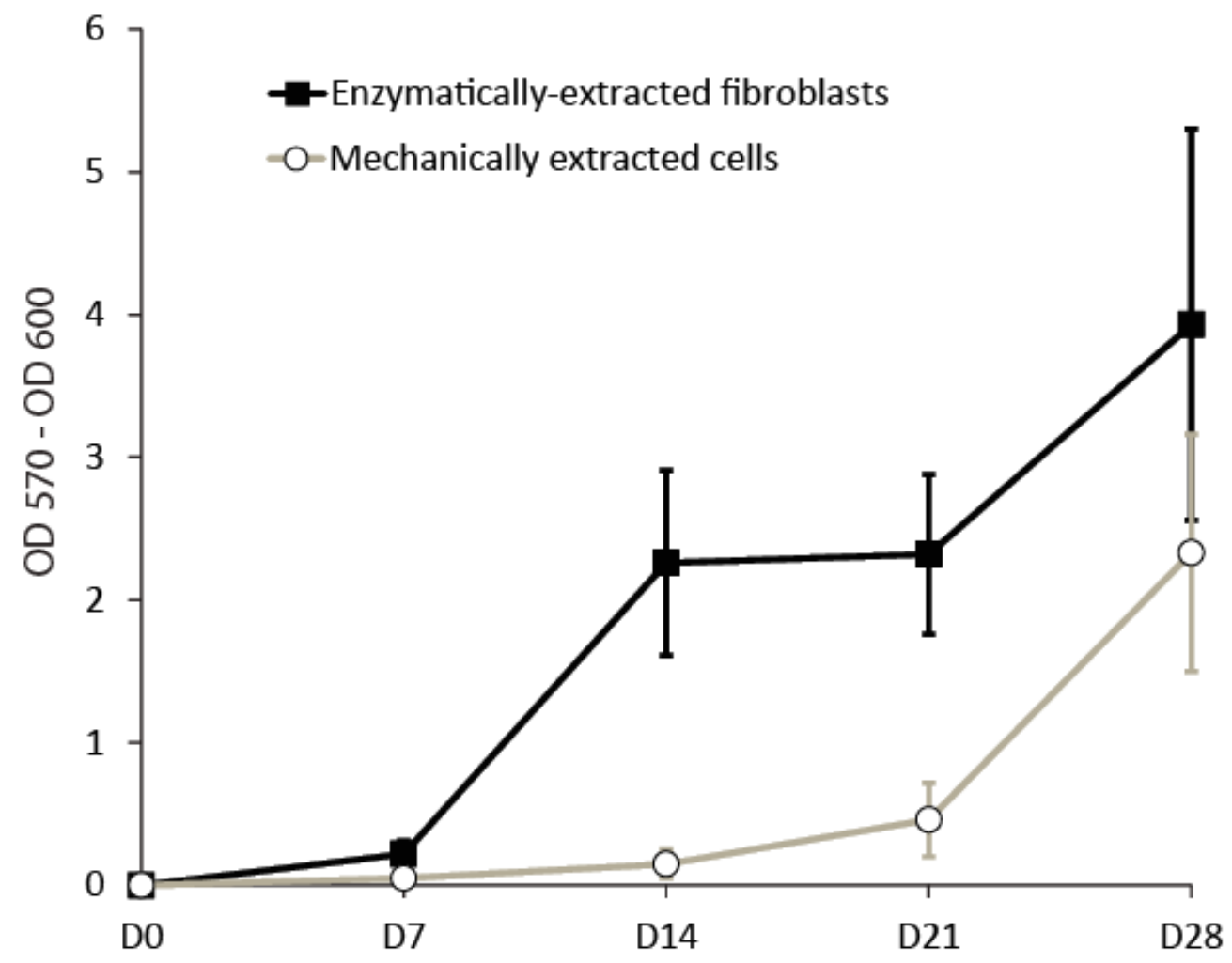

Figure 2: Monitoring of cell proliferation (alamar blue measurement) of mechanically-extracted cells and enzymatically-extracted fibroblasts $3 D$ bioprinted in the R\&D bioink. Replicates were performed on 3 different biopsies and mean signals are represented. 

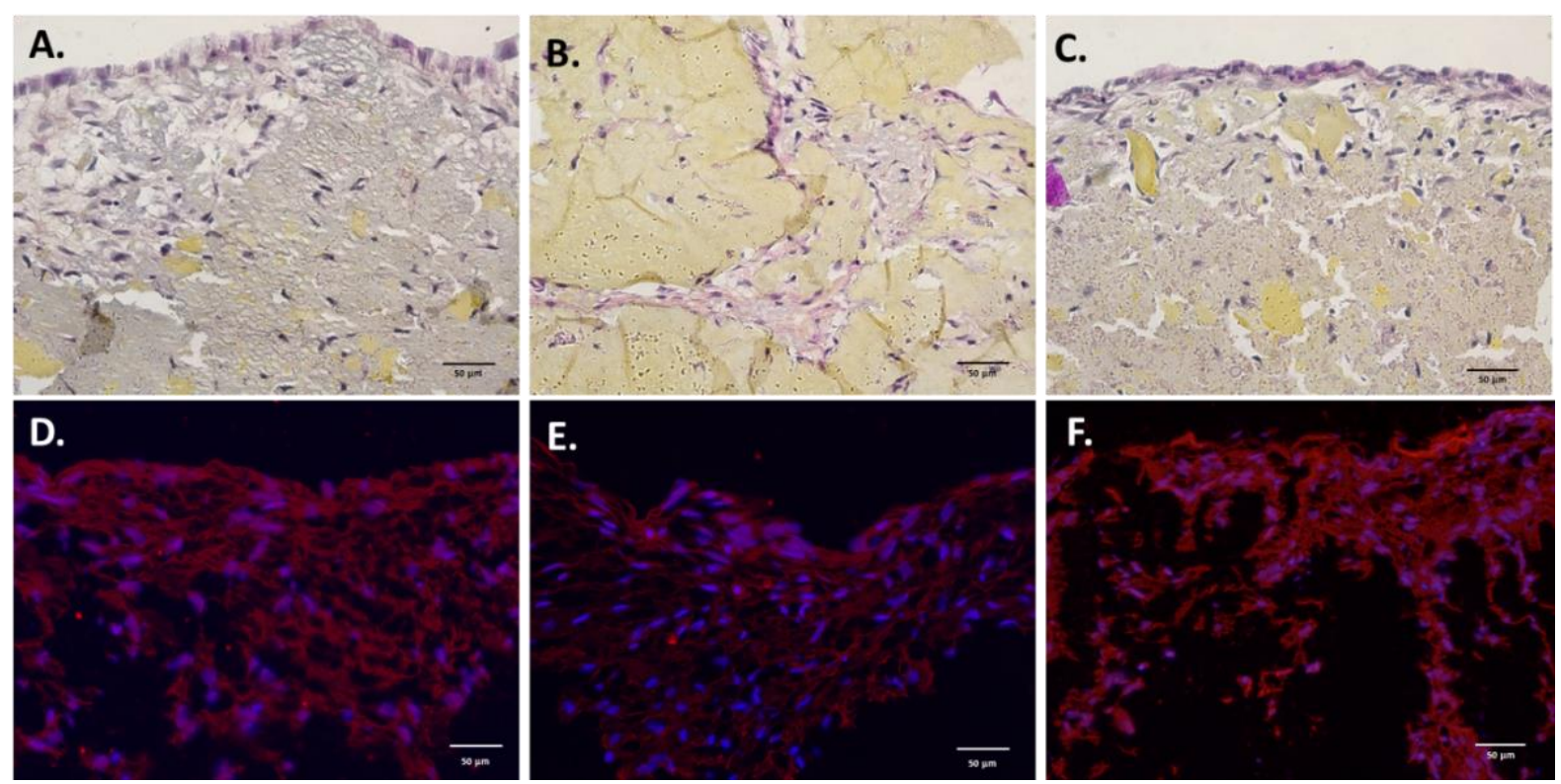

Figure 3: Histological analysis of dermis $3 D$ bioprinted with R\&D bioink seeded with enzymatically-extracted fibroblasts (A) or mechanically-extracted cells (B) - HPS staining after 6 weeks of culture. (C) Histological analysis of dermis 3D bioprinted with enzymatically-extracted fibroblasts in medical grade bioink. Nuclei were here stained in blue-violet by the hematoxylin, cytoplasm was stained in pink by the phloxine and collagen fibers were stained in orange-pink by saffron. Fluorescent microscopy observations of immunolabelled collagen I of dermis $3 D$ bioprinted with R\&D bioink seeded with enzymatically-extracted fibroblasts $(D)$ or mechanically-extracted cells (E) after 6 weeks of culture. (F) Fluorescent microscopy observations (after 6 weeks of culture) of immunolabelled type I collagen of dermis 3D bioprinted with enzymatically-extracted fibroblasts in medical grade bioink Type I collagen appears in red and nuclei are counterstained in blue by Hoechst. (scale bar $50 \mu \mathrm{m}$ ). Negative control immunolabelling of collagen can be found in Supplementary information 2. 


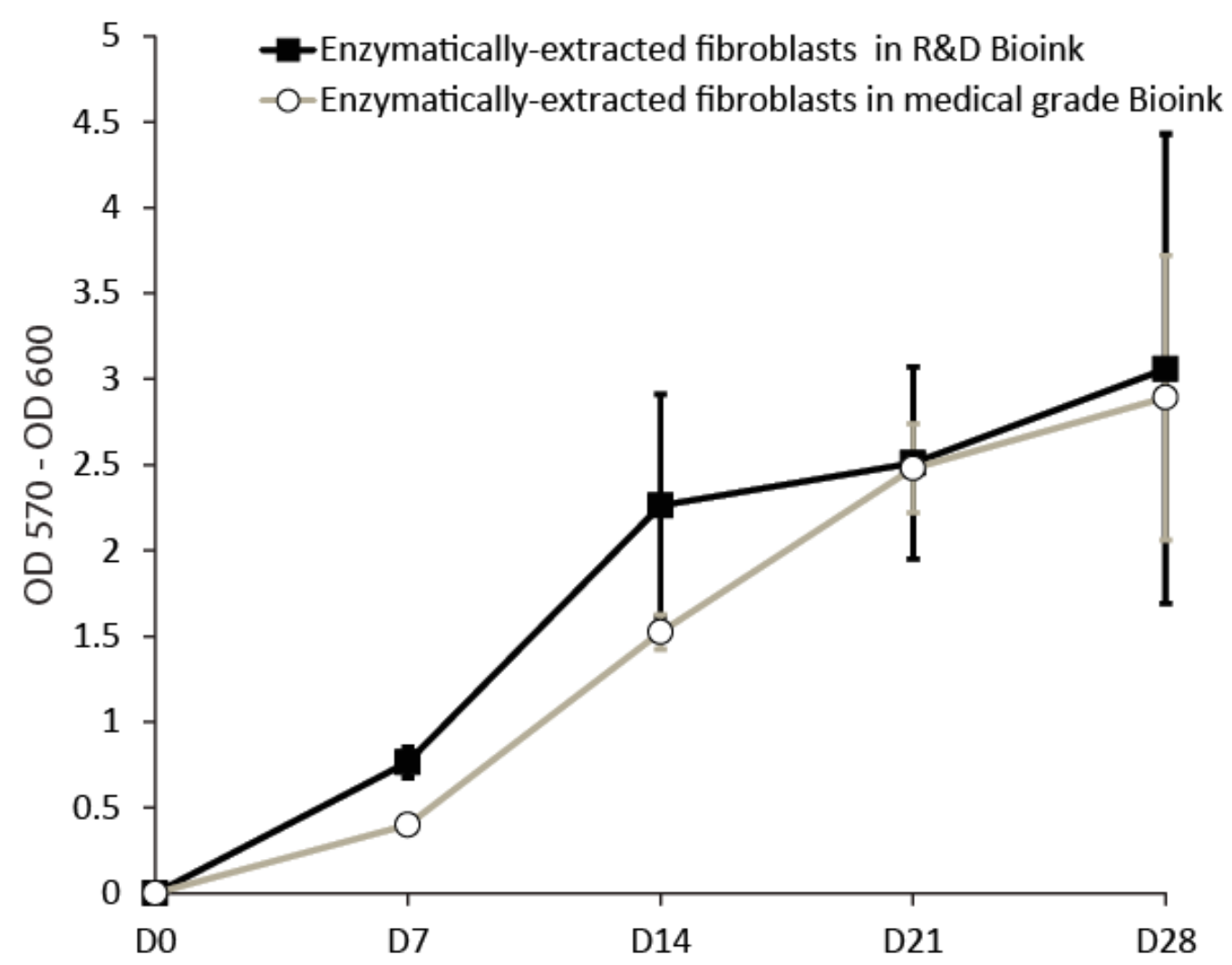

Figure 4: Monitoring of enzymatically-extracted fibroblasts proliferation after $3 D$ bioprinting in the R\&D and medical grade bioinks. Measurements were performed using alamar blue protocol at D7, D14, D21 and D28. Replicates are 3 different bioprinted dermis. 


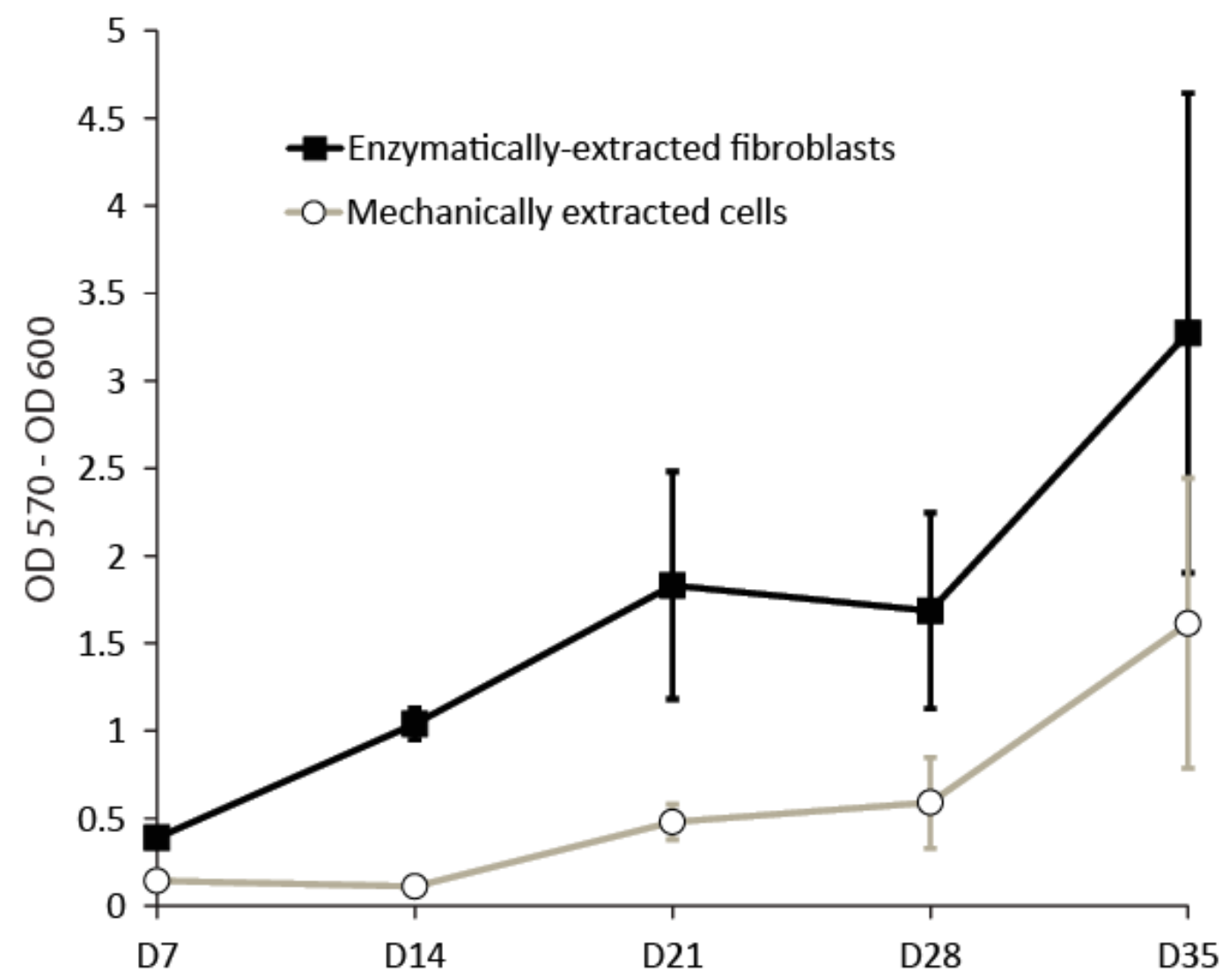

Figure 5: Monitoring of cell proliferation after 3D bioprinting of enzymatically-extracted fibroblasts and mechanically-extracted cells in the medical grade bioink. Measurements were performed using alamar blue protocol at D7, D14, D21, D28 and D35. Replicates are 3 different 3D bioprinted dermis. 

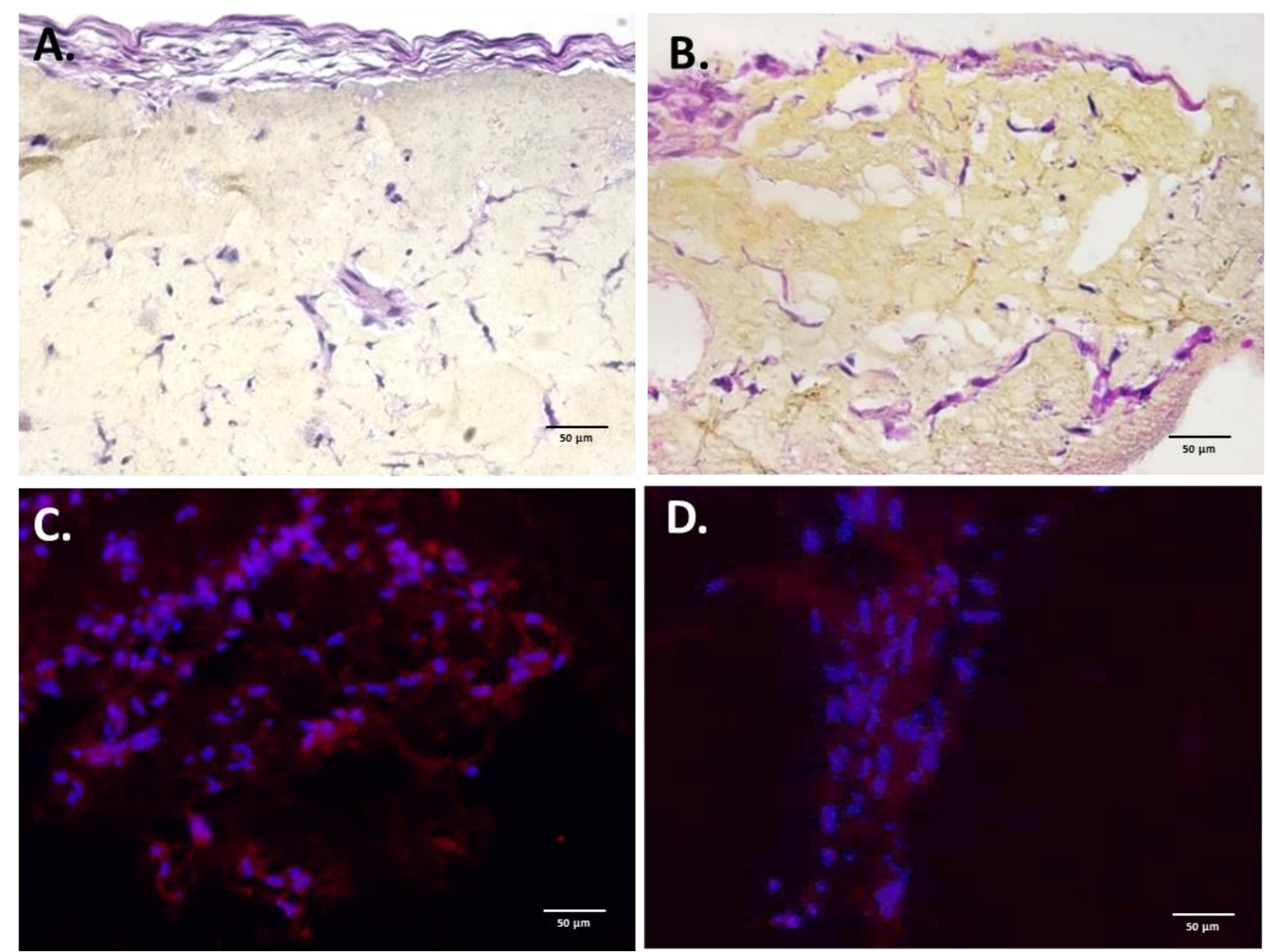

Figure 6: Histological analysis (HPS coloration after 6 weeks of culture) of dermis 3D bioprinted with medical grade bioink seeded with enzymatically-extracted fibroblasts (A) and mechanically-extracted cells (B). Nuclei were here stained in blue-violet by the hematoxylin, cytoplasm were stained in pink by the phloxine and collagen fibers were stained in orange-pink by saffron. Fluorescent microscopy observations (after 6 weeks of culture) of immunolabelled collagen I of dermis 3D bioprinted with medical grade bioink seeded with enzymaticallyextracted fibroblasts (C) and mechanically-extracted cells (D). Type I Collagen appears in red and nuclei are counterstained in blue by Hoechst. (scale bar $50 \mu \mathrm{m}$ ) 
A. Control Wound

Day 5
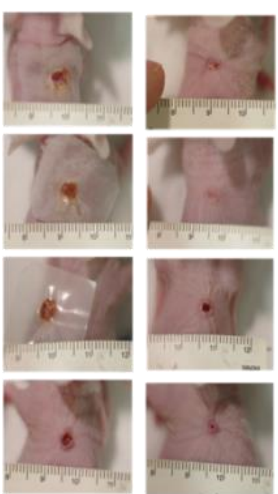

Bioink treated

Day 5
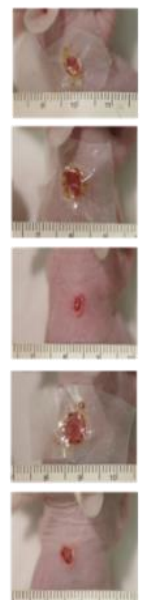

Day 7
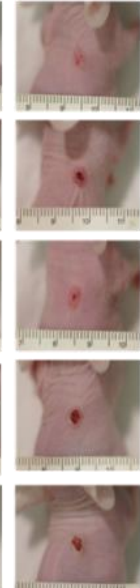
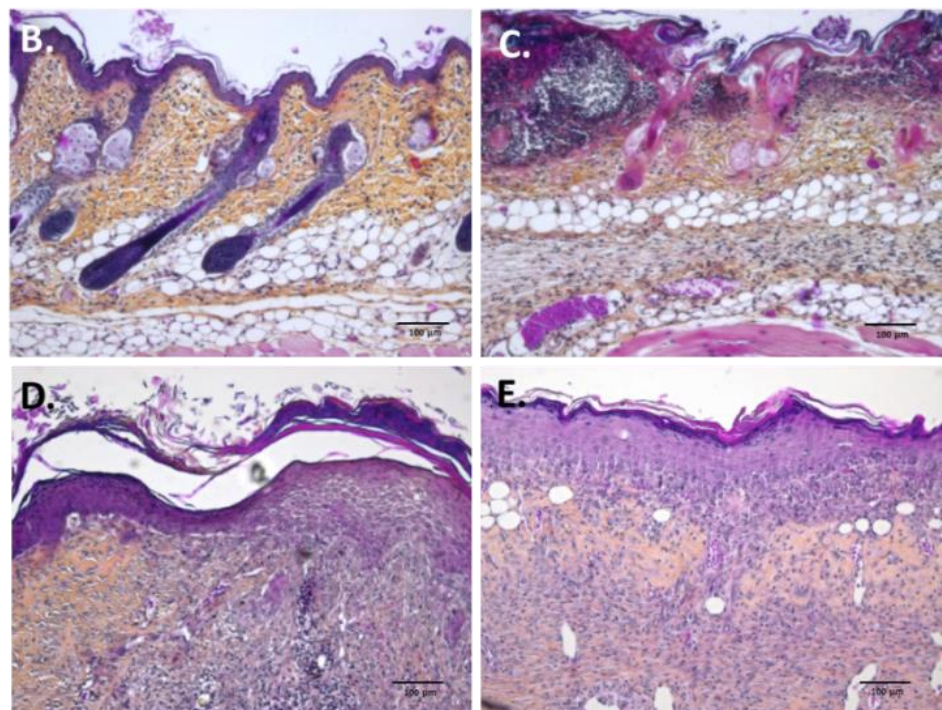

Figure 7: A) Macroscopic images of the control and bioink treated wounds at day 5 and day 7.

Histological analysis of mouse skin biopsies after HPS coloration: (B) normal mouse skin, (C) deep second degree burn model before debridement, (D) deep second degree burn model control at $D 7$ and (E) deep second degree burn model covered with bioink, at D7. Nuclei were here stained in blue-violet by the hematoxylin, cytoplasm stained in pink by the phloxine and collagen fibers stained in orange-pink by saffron. (scale bar $100 \mu \mathrm{m}$ ) 
Supplementary information 1: Images of fibroblasts and keratinocytes onset of proliferation from microexplants.

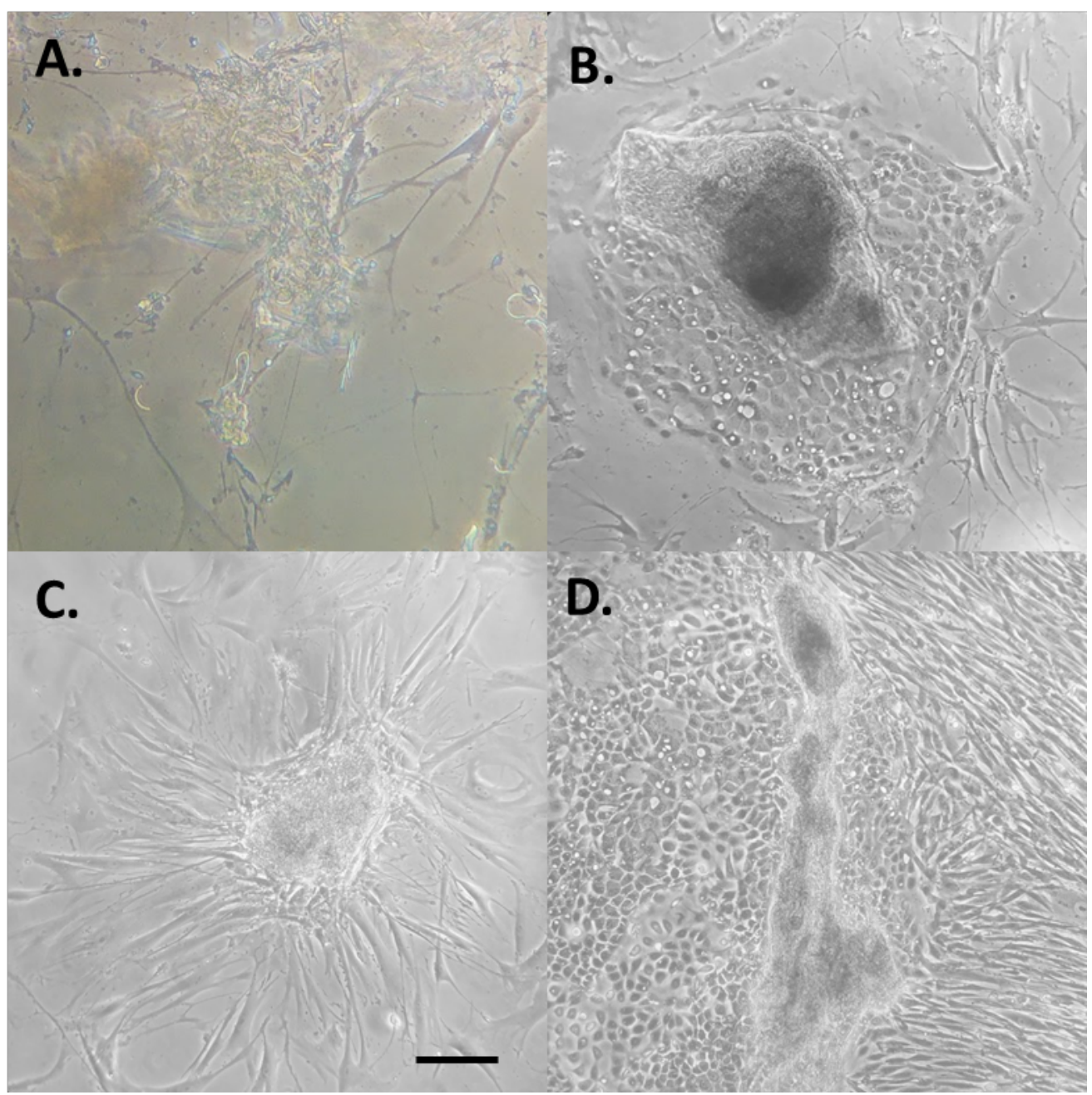

Observation of clones of keratinocytes $(\mathrm{KC})$ and fibroblasts $(\mathrm{Fb})$ after mechanical extraction with spleen 1 program at $D 1 A), D 10 B) \& C$ ) and $D 21 D$ ). One day after extraction, only microexplants are visible $A)$. At $D 10$, clones of $K C B$ ) and $F b C$ ) begin to appear and are recognizable by their typical morphology. At D21, both cell populations are observable on the same field of observation.

Scale bar $50 \mu \mathrm{m}$ 
Supplementary information 2: Negative control of type I collagen immunolabelling.

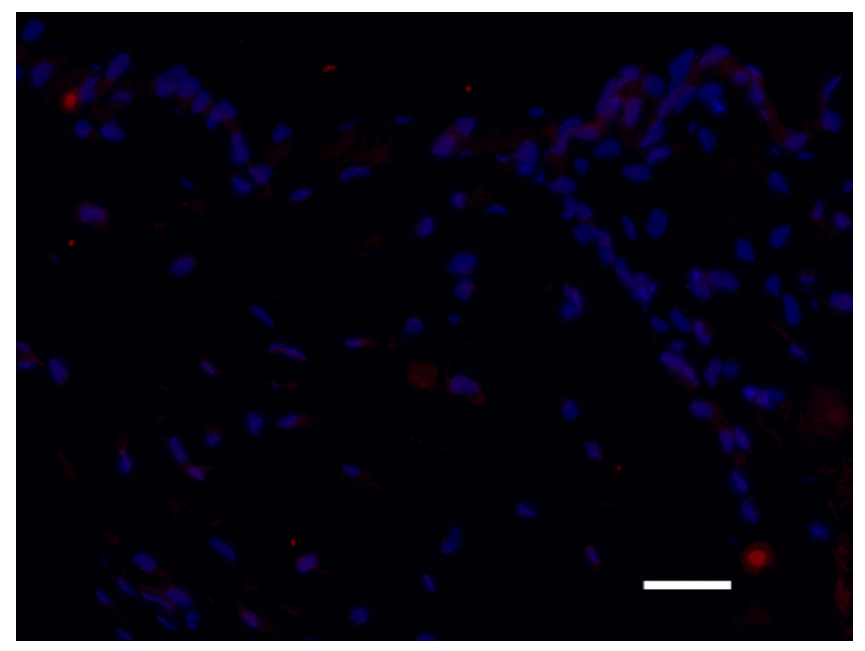

Fluorescent microscopy observations of immunolabelled collagen I in the absence of anti-type I collagen antibodies. Type I Collagen appears in red and nuclei are counterstained in blue by Hoechst. (scale bar $50 \mu \mathrm{m}$ ) 
Supplementary information 3: Immunolabelling of human Vimentin within the 3D bioprinted dermis.

A. Enzymatically-extracted fibroblasts
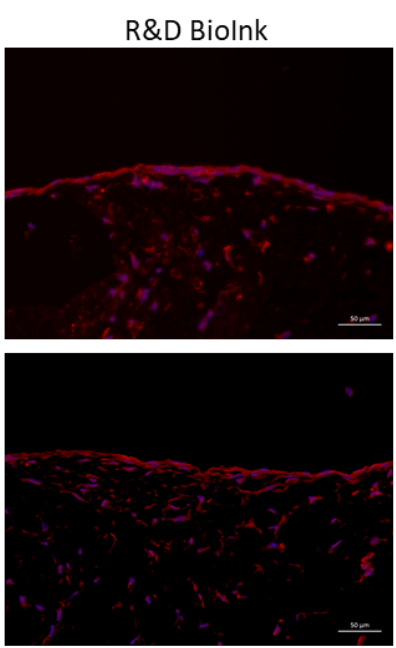

B.

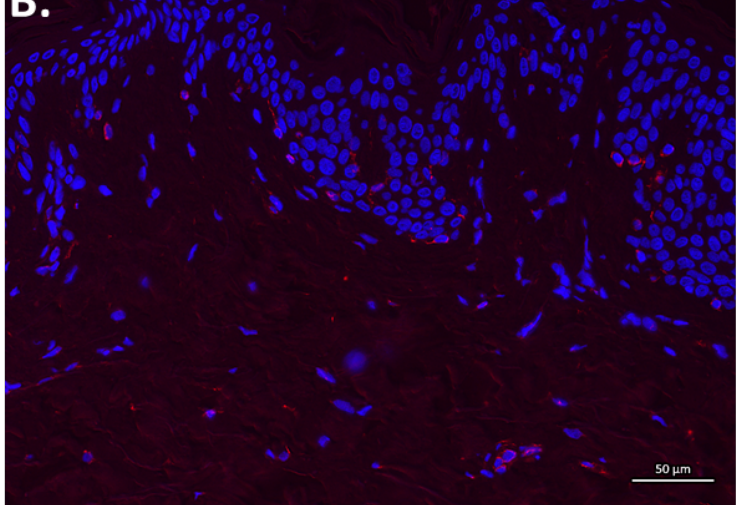

Mechanically-extracted cells

Medical grade Biolnk
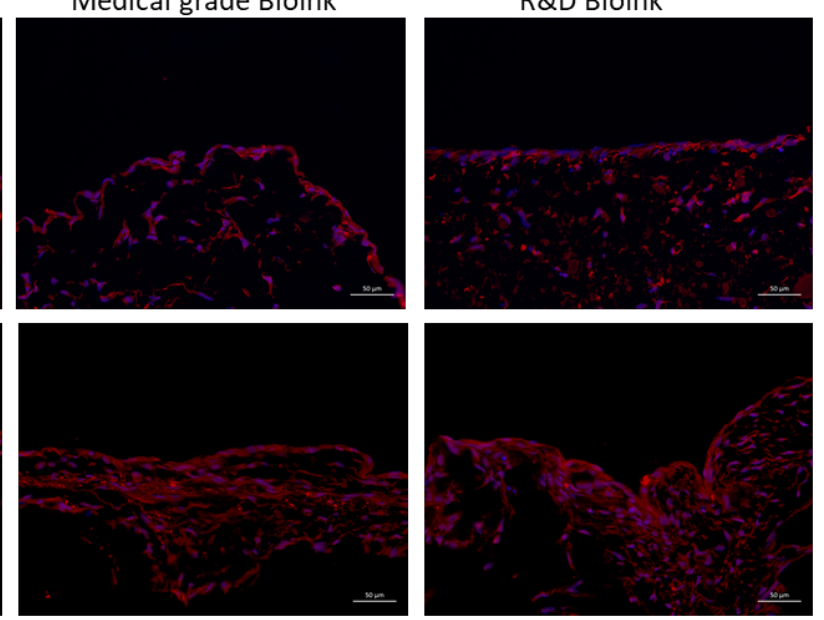

C.

A) Fluorescent microscopy observations of immunolabelled human Vimentin of dermis $3 D$ bioprinted with $R \& D$ or medical grade bioink seeded with enzymatically-extracted fibroblasts or mechanically-extracted cells. Images after 5 and 6 weeks of culture.

B) Fluorescent microscopy observations of immunolabelled human Vimentin in normal human skin dermis, together with negative control without anti-vimentin antibody.

Nuclei counterstained in blue by Hoechst. 
Supplementary information 4: Immunolabelling of human Pancytokeratin within 3D bioprinted dermis.

\section{A. Enzymatically-extracted fibroblasts}

R\&D Biolnk
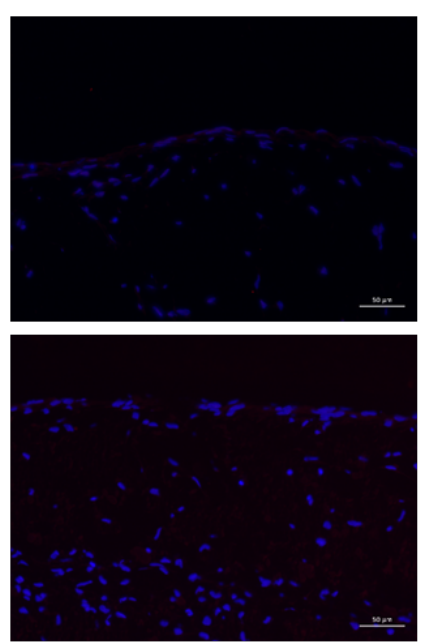

B.

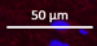

Medical grade Biolnk

\section{Mechanically-extracted cells}
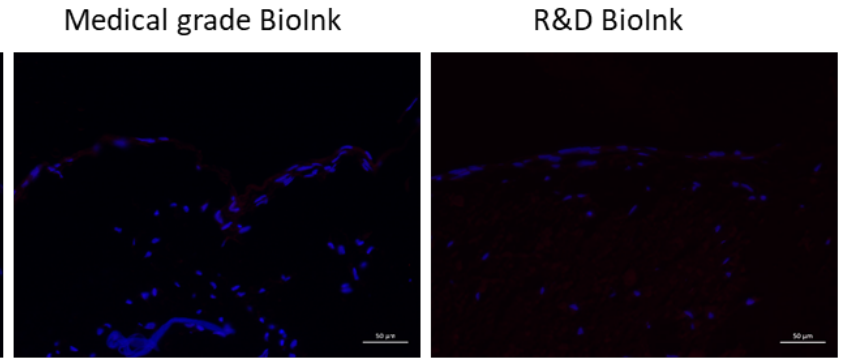

Medical grade Biolnk

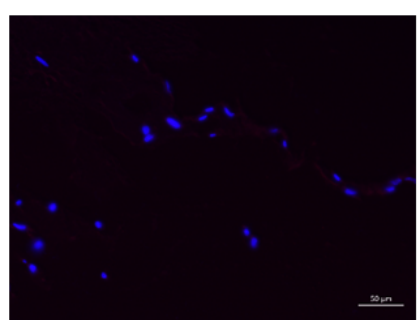

D35
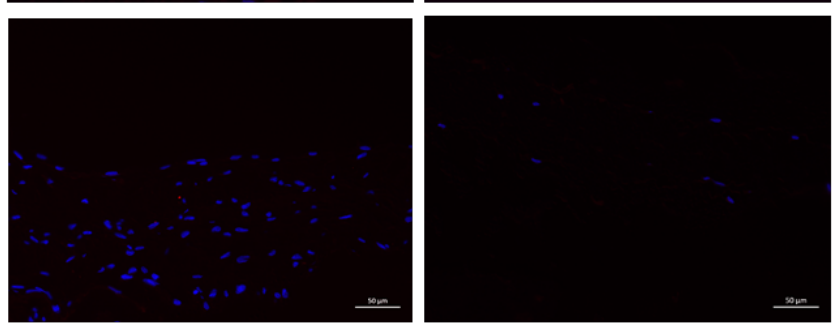

C.

A) Fluorescent microscopy observations of immunolabelled human Pancytokeratin of dermis $3 D$ bioprinted with $R \& D$ or medical grade bioink seeded with enzymatically-extracted fibroblasts or mechanically-extracted cells. Images after 5 and 6 weeks of culture.

B) Fluorescent microscopy observations of immunolabelled human Pancytokeratin in normal human skin dermis, together with negative control without anti-vimentin antibody.

Nuclei counterstained in blue by Hoechst. 
Supplementary information 5: Immunolabelling of human Pancytokeratin within the dermis bioprinted using enzymatically extracted fibroblasts and keratinocytes.

\section{A.}
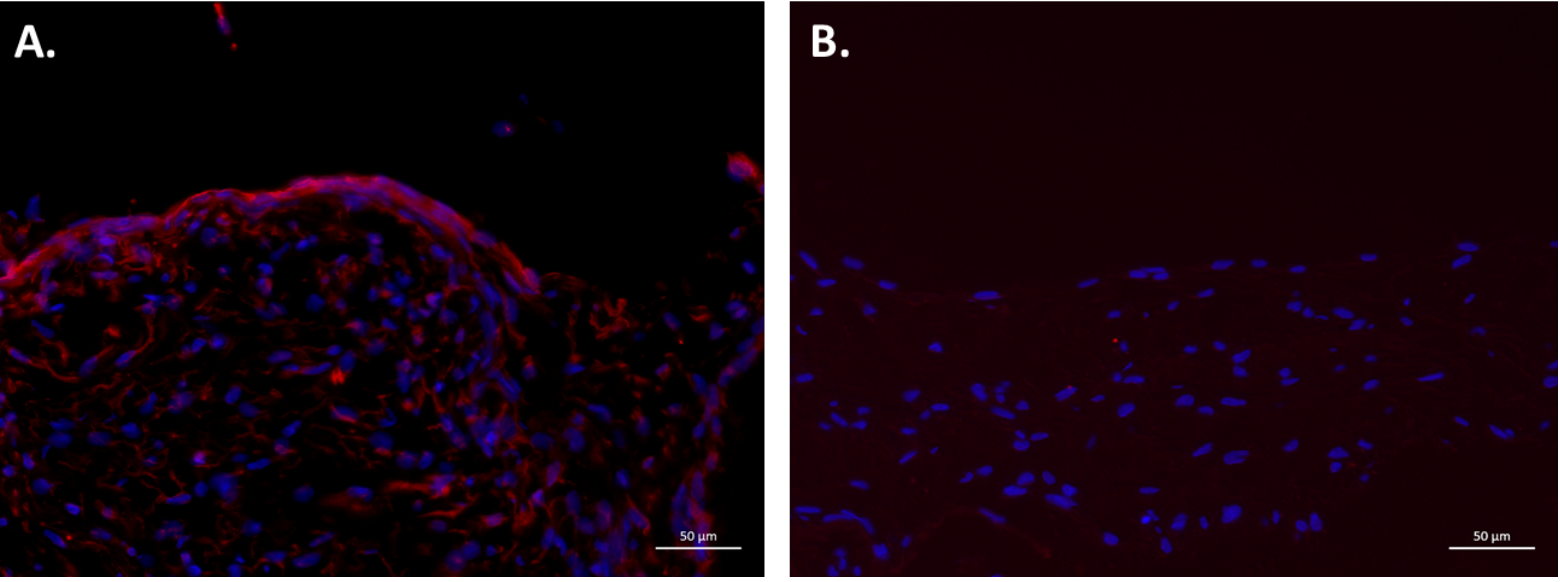

A) Fluorescent microscopy observations of immunolabelled human Vimentin of dermis 3D bioprinted with bioink seeded with enzymatically-extracted fibroblasts and keratinocytes. Images after 5 weeks.

B) Fluorescent microscopy observations of immunolabelled human Pancytokeratin of dermis 3D bioprinted with bioink seeded with enzymatically-extracted fibroblasts and keratinocytes. Images after 5 weeks. 
Supplementary information 6: Skin blood perfusion and temperature assessment for subcutaneous injected or wound covering bioink.

A.

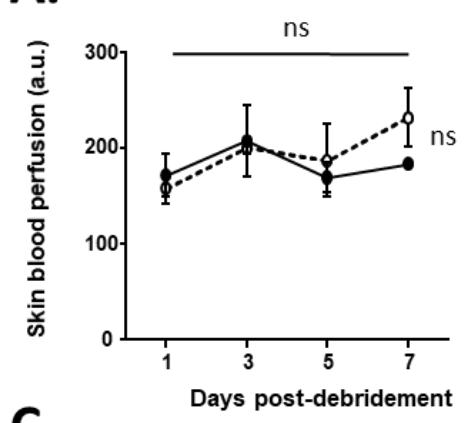

C.

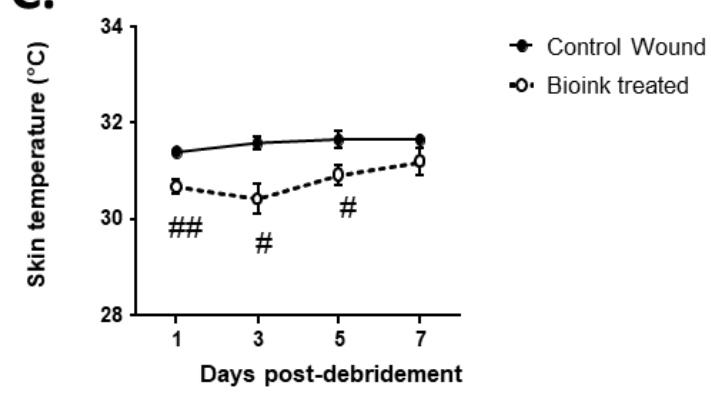

\#\# p< $0.01 ; \#$ p 0.05 vs Control Subcutaneous
B.

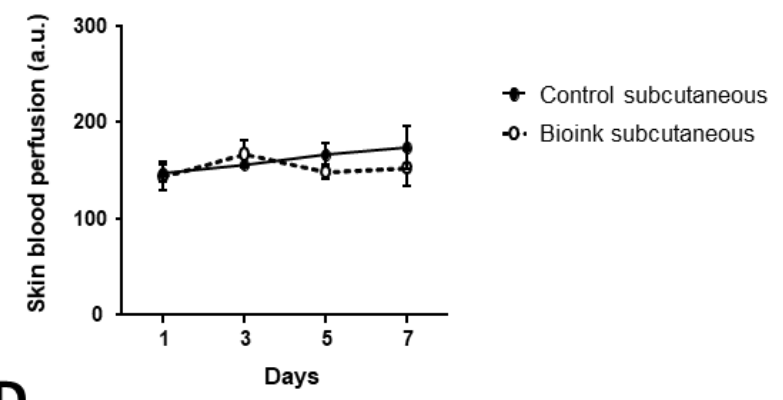

D.

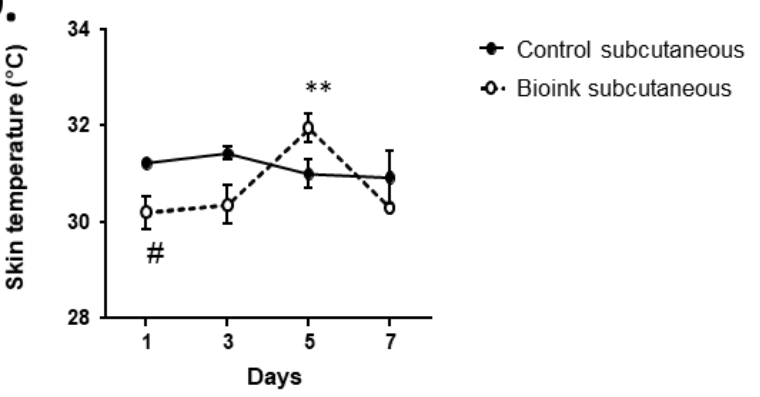

$\#$ p 0.05 vs Control Subcutaneous $* * p<0.01$ vs day 1

A) Measurement of blood perfusion for 7 days after debridement on the wound treated or not with the bioink. B) Measurement of blood perfusion for 7 days after subcutaneous injection of bioink. C) Measurement of temperature for 7 days after debridement on the wound treated or not with the bioink. D) Measurement of temperature for 7 days after subcutaneous injection of bioink. 
Supplementary information 7: Macroscopic in vivo observations of subcutaneous bioink injection.

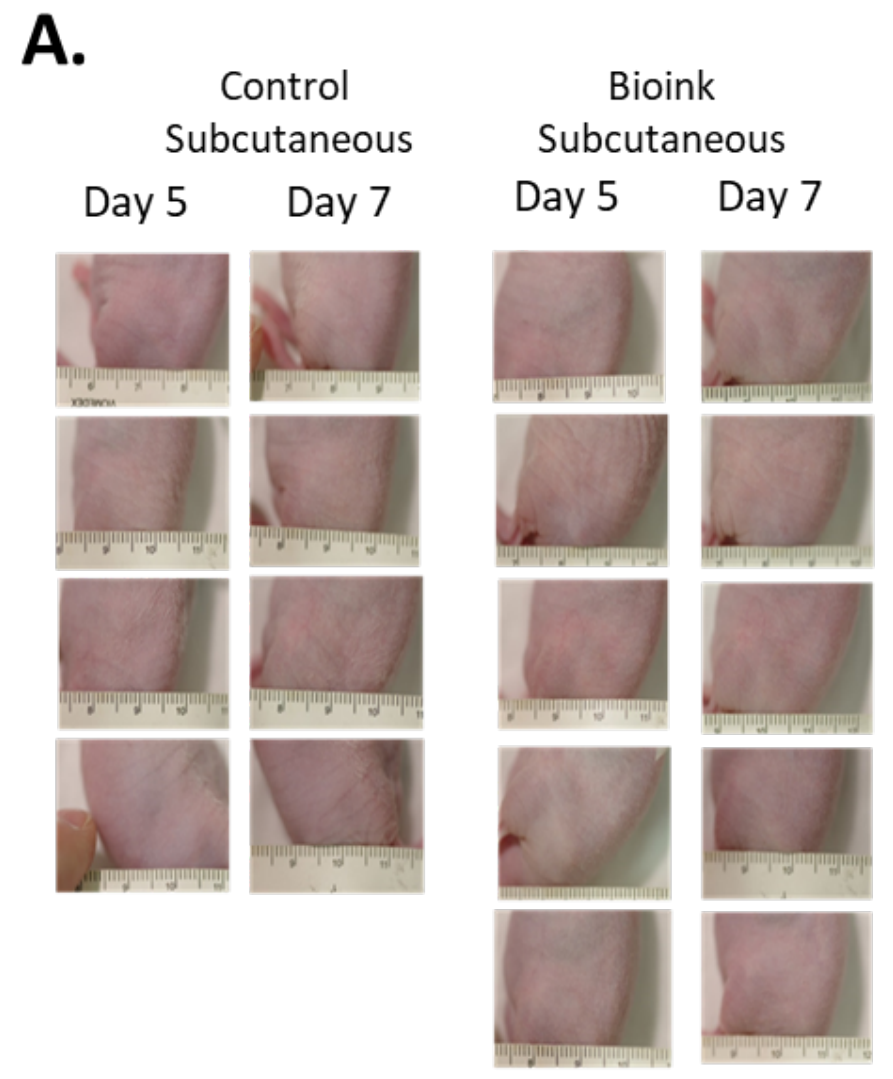

A) Macroscopic images of the subcutaneous injection sites at day 5 and day 7. 